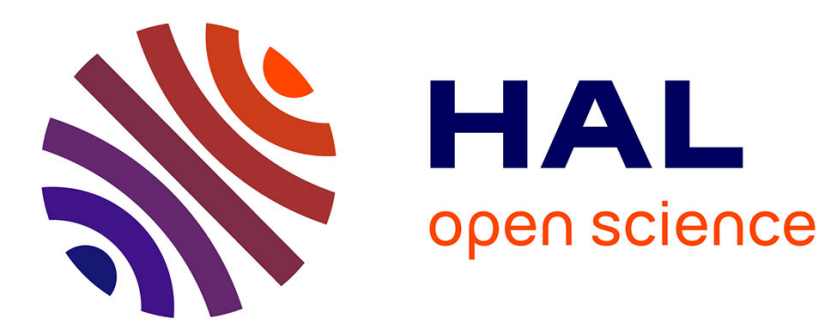

\title{
Increase in home bias in the Eurozone debt crisis: the role of domestic shocks
}

\author{
Camille Cornand, Pauline Gandré, Céline Gimet
}

\section{To cite this version:}

Camille Cornand, Pauline Gandré, Céline Gimet. Increase in home bias in the Eurozone debt crisis: the role of domestic shocks. 2014. halshs-01015475v3

\section{HAL Id: halshs-01015475 \\ https://shs.hal.science/halshs-01015475v3}

Preprint submitted on 16 Sep 2015

HAL is a multi-disciplinary open access archive for the deposit and dissemination of scientific research documents, whether they are published or not. The documents may come from teaching and research institutions in France or abroad, or from public or private research centers.
L'archive ouverte pluridisciplinaire HAL, est destinée au dépôt et à la diffusion de documents scientifiques de niveau recherche, publiés ou non, émanant des établissements d'enseignement et de recherche français ou étrangers, des laboratoires publics ou privés. 
UMR 5824

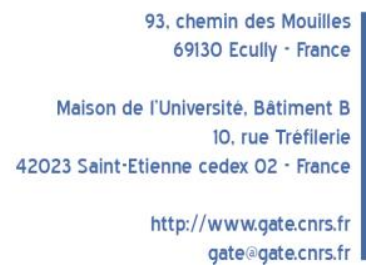

WP 1419 - Revised September 2015

\title{
Increase in home bias in the Eurozone debt crisis: the role of domestic shocks
}

\author{
Camille Cornand, Pauline Gandré, Céline Gimet
}

\begin{abstract}
:
One of the most striking consequences of the recent episode of sovereign debt market stress in the Eurozone has been the increase in the share of public debt held by the domestic sector in fragile economies. However, the causes and potential consequences of this increase were only given scarce attention in the literature on the Euro area sovereign debt crisis. In order to fill this gap, we first identify the shocks that impact the variation in the share of sovereign debt held at home in an SVAR model on a sample of Eurozone countries between 2002 and 2014, distinguishing between external and domestic shocks. Thanks to several alternative tests, we show that home bias in sovereign debt responds positively to country-specific fundamentals and expectations shocks but we find no evidence that the increase in home bias is destabilizing per se in the short-run. Second, a stylized theoretical model backed by the empirical results predicts that the consequences for sovereign debt crisis depend on the relative impact of domestic initial destabilizing shocks and increased home bias. The analysis suggests that an increase in home bias in times of sovereign debt stress, despite reflecting deteriorating fiscal conditions, may make default less likely.
\end{abstract}

\section{Keywords:}

Eurozone, Sovereign debt crisis, Home bias, Bayesian panel SVAR

JEL codes:

E4, E5, F3, G15

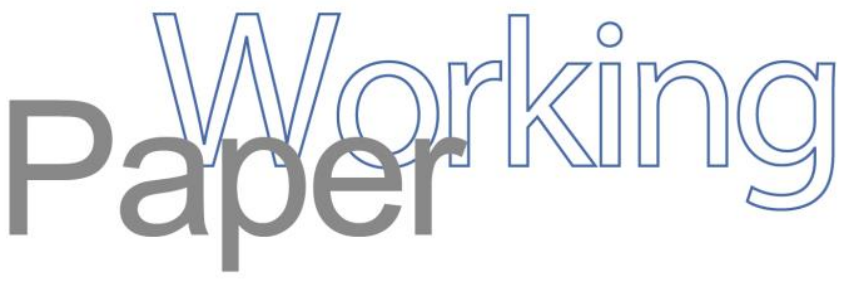




\title{
Increase in home bias in the Eurozone debt crisis: the role of domestic shocks*
}

\author{
Camille Cornand $^{\dagger} \quad$ Pauline Gandré $\quad$ Céline Gimet ${ }^{\S}$ \\ September 7, 2015
}

\begin{abstract}
One of the most striking consequences of the recent episode of sovereign debt market stress in the Eurozone has been the increase in the share of public debt held by the domestic sector in fragile economies. However, the causes and potential consequences of this increase were only given scarce attention in the literature on the Euro area sovereign debt crisis. In order to fill this gap, we first identify the shocks that impact the variation in the share of sovereign debt held at home in an SVAR model on a sample of Eurozone countries between 2002 and 2014, distinguishing between external and domestic shocks. Thanks to several alternative tests, we show that home bias in sovereign debt responds positively to country-specific fundamentals and expectations shocks but we find no evidence that the increase in home bias is destabilizing per se in the short-run. Second, a stylized theoretical model backed by the empirical results predicts that the consequences for sovereign debt crisis depend on the relative impact of domestic initial destabilizing shocks and increased home bias. The analysis suggests that an increase in home bias in times of sovereign debt stress, despite reflecting deteriorating fiscal conditions, may make default less likely.
\end{abstract}

JEL classification: E4, E5, F3, G15.

Keywords: Eurozone, Sovereign debt crisis, Home bias, Bayesian panel SVAR.

${ }^{*}$ We thank Stephan Sauer, Andrea Bonilla Bolaños, Aurélien Eyquem, Nicolas Houy, Bruno Ziliotto, as well as participants at the 11th Infiniti Conference, the 11th Macrofi workshop, the 2nd Finandebt Conference, the 63rd AFSE Conference and the 2nd Lyon-Turin workshop, in particular our discussants Livia Chitu and Matthieu Charpe, for helpful comments and discussions. We also wish to thank the editor Pr. Sushanta Mallick and three anonymous reviewers for very valuable remarks and suggestions.

† cornand@gate.cnrs.fr, University of Lyon, F-69007 Lyon, France, and CNRS, GATE Lyon-St Etienne, UMR 5824, F-69130, Ecully, France.

${ }_{\ddagger}^{\ddagger}$ pauline.gandre@ens-lyon.fr, corresponding author, University of Lyon, F-69007 Lyon, France, CNRS, GATE Lyon-St Etienne, UMR 5824, F-69130, Ecully, France and Ecole Normale Supérieure de Lyon, F-69007 Lyon, France.

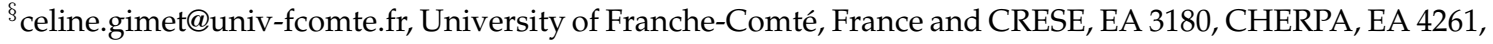
and GATE Lyon St-Etienne, UMR 5824, France. 


\section{Introduction}

One of the most striking and seemingly surprising consequences of the recent episode of sovereign debt market stress in the Eurozone has been the increase in the share of public debt held by the domestic sector in fragile economies (Merler and Pisani-Ferry (2012), and Van Riet (2014)). Despite a deep turmoil period on the public debt market of the peripheral Eurozone countries, residents in GIIPS countries (Greece, Ireland, Italy, Portugal, Spain) significantly increased their purchases of domestic sovereign debt, both in volume and in proportion. Thus, by mid-2012, the share of sovereign debt securities held by the domestic sector was above $60 \%$ in Italy and above $70 \%$ in Spain, beyond the pre-Euro area levels, in the context of a decline in financial integration in Europe (Raileanu-Szeles and Albu, 2015). On the contrary, home bias in sovereign $\operatorname{debt}^{1}$ kept decreasing in Germany, moving from around $65 \%$ in 2000 to less than $40 \%$ by the end of 2014 . The causes and consequences of the increase in home bias in sovereign debt in fragile economies were given only scarce attention in the literature on the Euro area sovereign debt crisis. In this paper, we fill this gap by empirically analyzing the role of domestic shocks on home bias and by providing a stylized model backed by our empirical results to derive the potential consequences of the increase in home bias in the Euro area.

In contrast to Andritzky (2012)'s interpretation of the recent increase in home bias in the Eurozone - which emphasizes the role of global factors -, divergent trends among countries sharing a similar currency and their coincidence with the Eurozone sovereign debt crisis suggest that home bias in peripheral countries increased following country-specific shocks affecting sovereign debt sustainability. Brutti and Sauré (2015) highlight that repatriation of assets from foreign to domestic creditors mainly impacted fragile economies and sovereign debt relative to other assets. Van Riet (2014) provides evidence on Euro area national governments' attempts to create a captive domestic investor base on the sovereign bonds market in response to fiscal stress episodes, notably in Ireland, Portugal and Spain. In most of the fragile economies of the zone, the rise in home bias was indeed driven by decreases in foreign purchases of domestic public debt simultaneous with increases in domestic purchases. This supports the idea that in times of sovereign debt stress, incentives to buy domestic sovereign debt increased (or decreased less) for domestic creditors relative to those of foreign creditors, as argued by Battistini et al. (2014). In the same line, MacDonald et al. (2015) show more generally that the

\footnotetext{
${ }^{1}$ As Acharya et al. (2014), we consider that 'Home bias in government debt is total home sovereign debt as a share of total sovereign debt' (p. 54). Our definition may differ from the commonly accepted definition, according to which home bias is the propensity of investors to make financial investments in their home countries rather than in foreign markets (home bias in portfolios). For comparability and data availability issues, in most countries, we measure home bias as the share of domestic holdings of general government debt securities, rather than of total sovereign debt.
} 
Eurozone countries were mostly responsive to their own domestic shocks in the recent crisis episode. In addition, empirical literature documented the importance of self-fulfilling factors for explaining the Eurozone sovereign debt crisis (De Grauwe and Ji (2013), Bruneau et al. (2014), and Schumacher (2014)). These papers - relying on empirical applications to sovereign debt crises of the theoretical literature on second-generation speculative attack models (Obstfeld, 1996) - showed that peripheral Eurozone economies with relatively good fiscal fundamentals faced strong increases in sovereign bonds spreads, due to episodes of exogenous distrust in international financial markets. ${ }^{2}$ These several empirical elements provide motivation for investigating the impact of domestic shocks on the evolution of home bias in sovereign debt and for studying both the impact of fundamentals and expectations shocks on the dynamics of home bias, as the latter is expected to respond to domestic probability of default shocks.

Furthermore, while the recent increase in home bias in the Euro area appears to be a consequence of the sovereign debt crisis, it may also have an impact per se on sovereign debt sustainability. Indeed, the literature emphasized three distinct mechanisms through which home bias might affect the probability of default. The first one is that a higher home bias increases the internal cost of default, as it raises the negative impact of default on the domestic economy (Mengus (2014), and Acharya et al. (2014)). Indeed, it implies that a higher share of domestic creditors, notably resident banks, are not repaid on their holdings of domestic sovereign bonds following default. The second one is that the cost of taxation for the government decreases in the home bias. Gros (2012) argues that domestic taxpayers are less reluctant to pay taxes for financing sovereign debt when they are holding a higher share of the debt. Therefore, a higher home bias lowers the political cost of taxation for the government. In this view, an increase in home bias in sovereign debt decreases the government's incentives to default ceteris paribus. Gennaioli et al. (2014) provide empirical evidence in favor of this stabilizing effect: they show that the larger the exposure of domestic banks to sovereign bonds, the more costly the default for the domestic economy through its ex post impact on private credit. However, the third effect identified in the theoretical literature advocates a destabilizing impact of increased home bias. Thus, Broner et al. (2014) argue that because of financial frictions, higher purchases of domestic sovereign debt by the resident sector lead to crowding-out effects by disrupting productive investment, and thus lowers growth. Nevertheless, this last effect has not yet been empirically tested in the literature.

\footnotetext{
${ }^{2}$ First models of self-fulfilling sovereign debt crises include Calvo (1988) and Cole and Kehoe (2000). This category of models was recently applied to the Eurozone debt crisis (Lorenzoni and Werning (2013), Corsetti and Dedola (2011), Aguiar et al. (2014), and Blot et al. (2015)).
} 
Analyzing the relation of home bias to country-specific variables to decipher the causes of its recent increase in the Euro area and investigating its potential consequences for sovereign debt crisis thus seems to matter for better understanding the specific features of the so-called Eurozone crisis. Accordingly, this paper empirically identifies the macroeconomic shocks that can prompt home bias in sovereign debt to increase. Using a Bayesian Structural VAR (SVAR) estimation that relies on a new database built from national sources in a sample of seven Eurozone countries in the 2002-2014 period, we show that domestic fundamental shocks and country-specific expectations shocks do contribute to increased home bias in our sample. In addition, we find no evidence in favor of the fact that, everything else being equal, an increase in home bias leads to a decrease in the growth rate in the short-run. In order to go deeper into the understanding of the empirical results and their implications, we then propose a simple model of sovereign debt crisis in a monetary union, the assumptions of which are supported by our empirical results. The model provides microfoundations to explain the recent increase in home bias in the Eurozone and, by modeling the transmission channels of initial probability of default shocks, it enables to derive a simple prediction: an increase in home bias is associated with a change in the government's strategic decision regarding default if, and only if, the destabilizing impact of the initial shock is high enough relative to the potentially stabilizing impact of the increase in home bias. In other words, an increase in home bias during a debt crisis may make default less attractive for national governments, provided that deterioration in fundamentals and in expectations is comparatively not too strong.

The literature on the Eurozone sovereign debt crisis paid rather scarce attention to the increase in home bias in public debt in comparison with the possibly strong consequences it may have for fiscal strategic decisions. Empirically, Battistini et al. (2014) study how home bias responds to yield differentials in the Eurozone. Brutti and Sauré (2015) investigate the impact of experiencing a crisis (defined by a threshold on bond yields) on home bias with a static panel model. Because none of those papers aim at addressing the consequences of an increasing home bias on the decision of default, they focus on home bias in banks' portfolios, defined as the domestic sovereign debt holdings of the banks in one country scaled by their total assets. By contrast, we address a general measure of home bias in sovereign debt, the one that matters for the government's decision. Andritzky (2012) focuses on disentangling the causal relationship between sovereign bond yields and the share of debt held by foreigners in a bi-variate panel VAR specification, whereas we identify structural shocks and distinguish between fundamental and expectations shocks, relying on an updated dataset. To the 
best of our knowledge, no other work investigates the empirical relationship between home bias in sovereign debt and domestic variables related to sovereign debt sustainability in the Eurozone by distinguishing fundamental and self-fulfilling drivers and by investigating bi-directional causalities. On the theoretical side, Broner et al. (2014) argue that creditors' discrimination can favor purchases of sovereign debt by domestic investors, which triggers crowding-out effects and may lead to selffulfilling dynamics. Mengus (2014) states that home bias in public debt results from the possibility of post-default bailouts to domestic creditors and identifies the consequences for the borrowing capacity of the sovereign. Gennaioli et al. (2014) focus on the impact of financial development on sovereign default and show that more developed financial institutions and higher exposure of banks to domestic public debt decrease the probability of default by raising the cost of default. Our paper thus aims at completing recent theoretical literature by providing empirical results on the relationship between home bias and country-specific variables and by supporting our simple theoretical model directly by empirical results, in order to be able to account specifically for the Eurozone sovereign debt crisis features.

The next section presents empirical facts about home bias in the Eurozone and performs the econometric analysis which is useful for selecting the main assumptions of our theoretical model. Section 3 develops the model of debt crisis with endogenous home bias. Section 4 concludes the paper.

\section{Home bias in the Eurozone}

In the following section, we present recent features in the origin and evolution of home bias in sovereign debt that are specific to the Eurozone. We then identify the shocks that explain most of the variation in home bias in our sample using a panel SVAR model completed with country-specific tests and we provide additional results on the impact of home bias on the other endogenous variables.

\subsection{Evolution and origin of home bias in sovereign debt}

Four main features regarding the recent evolution of home bias in sovereign debt can be identified in the Eurozone as shown in Figures 1, 2, and 3. ${ }^{3}$

First, there has been an increase in home bias during the Euro area sovereign debt crisis. The pro-

\footnotetext{
${ }^{3}$ Notice that the facts that we emphasize here deal with variation in home bias, and not with the level of home bias, in a particular context of stress on the sovereign debt market in a monetary union. Consequently, we focus on the causes and consequences of a short-term increase in home bias in this particular context rather than on structural factors. The case we investigate is thus different from that of Japan, where home bias in public debt is known to be structurally high (90\% in the first quarter of 2012, according to Andritzky's database), but stable.
} 


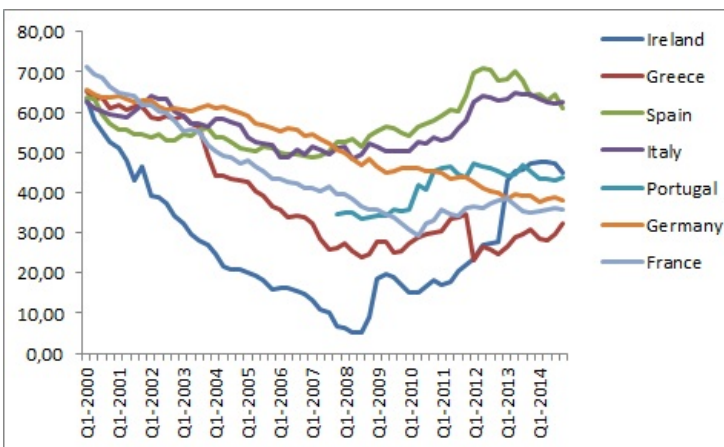

a) Home bias in the Eurozone (\% of general government debt held by residents)

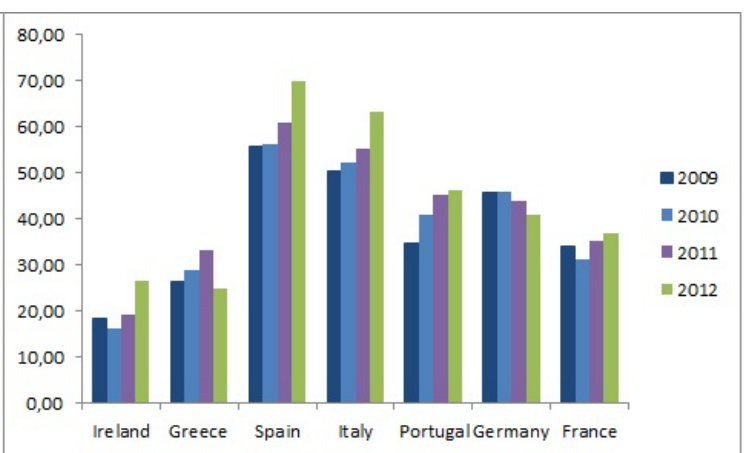

b) Recent evolution in home bias (\% of general government debt)

Figure 1: Evolution of home bias - Sources: National Central Banks (a, b).

portion of domestic holdings of public debt significantly decreased since the creation of the Eurozone in 1999, revealing a deepening of European financial markets integration (Figure 1 a). Nonetheless, home bias began increasing again in most Eurozone countries except Germany, in the aftermath of the global financial crisis and the consecutive debt crisis in the Eurozone. Thus, the increase in home bias started at the end of 2008 or the beginning of 2009 in peripheral Eurozone countries, and in the beginning of 2010 in France.

Second, the increase in home bias seems to be higher in the most fragile Eurozone economies, the so-called GIIPS countries (Figure $1 \mathrm{~b}$ ).

Third, the increase in home bias displays distinct features across European countries. In Italy and

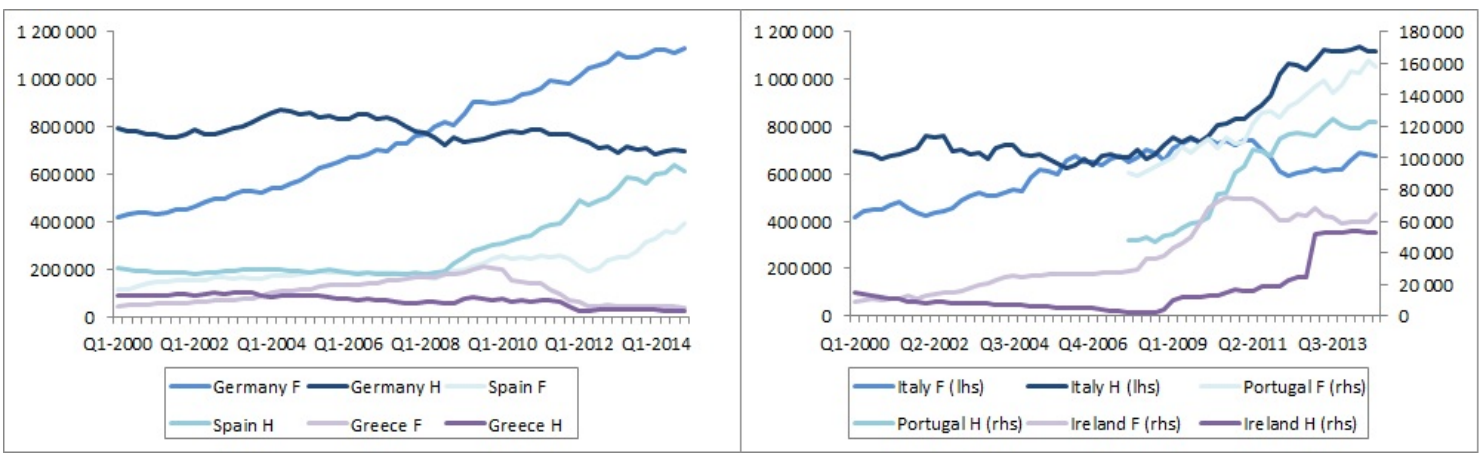

Figure 2: Foreign $(\mathrm{F})$ and domestic $(\mathrm{H})$ volumes of general government debt holdings (million euros) - Source: National Central Banks.

Ireland, the increase is due to a fall in the volume of sovereign debt securities held by non-residents simultaneous with a rise in the volume held by residents. In Spain, a similar evolution was first ob- 
served, but the volume of general government debt securities held by foreigners started to increase again around the year 2012, even though it rose more slowly than the volume held at home. In Greece, the increase in home bias is due to a fall in both volumes in the most recent quarters (Figure 2), with foreign holdings decreasing faster. In Portugal, the rise is due to the increasing volume of debt securities held by residents, which has recently grown faster than the volume held by non-residents (however, evolution in volumes are not available before 2007 for Portugal). ${ }^{4}$

Fourth, the banking and financial sectors hold a significant share of domestic public debt, which deepens the intertwining between sovereign debt risk and banking sector risk (Acharya et al., 2014). More notably, this intertwining has recently increased, with a stronger exposure of domestic banks to domestic sovereign debt (Figure 3). This feature is clearly more significant in the Eurozone compared

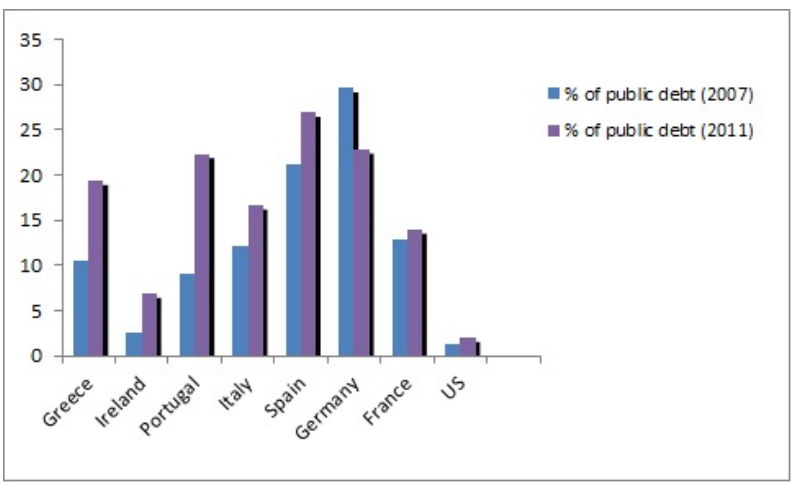

Figure 3: Evolution of domestic banks' sovereign debt holdings - Source: Merler and PisaniFerry (2012).

with the UK and the US.

We now conduct empirical tests to provide further insights on the exogenous factors that positively affect home bias and on the direct consequences of the increase in home bias on domestic variables.

\subsection{Empirical Tests}

We rely on a sample of seven Eurozone economies for which data on home bias in sovereign debt is available, and which faced either a significant increase in home bias (Greece, Ireland, Italy, Portugal,

\footnotetext{
${ }^{4}$ Note that the debt volumes displayed in Figure 2 are distinct from total general government debt volumes for most countries. We provide details on how the data on home bias were calculated for each country in Appendix A, based on data availability and comparability issues. In addition, the data on volumes in the case of France are not made available by the Bank of France.
} 
Spain), a more recent increase in home bias (France) or a decrease in home bias (Germany), ${ }^{5}$ between 2002:Q1 and 2014:Q4 for all countries in the sample except Portugal, for which data is available only from 2007:Q4 onwards. For the latter, a country-specific analysis is performed.

The start of the period of study is chosen so that it is the longest possible one while including only post-Euro area data - in order to focus on factors affecting home bias in the context of a monetary union - and so that all data is available for all quarters for all countries (except for Portugal for which tests are performed separately), which allows to rely only on official data without the need to use extrapolation methods. ${ }^{6}$ The VIX variable, which is widely used as a proxy for global risk aversion and uncertainty and which is included in our empirical model as explained below, enables to control for time variations related to the global financial crisis period.

The increase in home bias observed in most of the sample is sudden and approximately coincides with the start of the stress period on the Eurozone debt markets. Therefore, it seems consistent to interpret the increase in home bias as the result of unexpected exogenous shocks. This is why we investigate the impact of distinct shocks on the dynamics of home bias to identify the most explanatory ones in our sample, relying on a SVAR model.

The empirical model Distinct arguments support our empirical strategy. First, the SVAR model enables us to perform an analysis of unexpected shocks. Second, our identification strategy allows us to interpret the shocks in economic terms, differently to a simple VAR model. Third, an SVAR model makes it possible to analyze bi-directional causalities without facing endogeneity issues. Therefore, we can both determine the shocks that prompt home bias to respond positively and the impact of home bias shocks on the other variables in the model.

Our SVAR model includes 5 variables. In a first step, we identify the main sources of variation in home bias $(h b)$ in public debt and in a second step, we investigate the impact of home bias shocks on the other endogenous variables. We built a new dataset on home bias relying on national sources (national central banks). Whenever possible, our home bias variable measures the share of general government debt securities held by residents (in \% of total) rather than the share of total general government debt held at home for two reasons. First, for Ireland, France and Portugal, no time series on the decomposition between the resident sector and the foreign sector are available for total debt, whereas Germany is the only country in our sample for which the decomposition between the

\footnotetext{
${ }^{5}$ Even though our sample is limited by data availability, it includes the biggest Eurozone countries and all the GIIPS, on which concerns focused during the recent crisis.

${ }^{6}$ Most data is not available before 2002 and the period of study then allows to exclude the dot-com bubble/bust period.
} 
resident and the foreign sector is not available for debt securities over our whole period of study. Therefore, focusing on debt securities ensures more homogeneity in the cross-section data. Second, this variable allows to focus on marketable government debt which is widely traded between domestic and foreign investors, following Andritzky (2012). Appendix A provides details on the data we relied on for each country in our sample. Following the literature (Andritzky (2012), Battistini et al. (2014), and Brutti and Sauré (2015)), we focus on the share rather than on volumes because the share exhibits a common pattern in fragile economies in our sample and reflects the relative evolution in domestic and foreign holdings, which is expected to be affected following a shock to a country's sovereign risk, as the latter modifies domestic and foreign demand for domestic government debt securities in a distinct manner. Finally, volumes also depend on many other factors, such as the evolution of total debt (and thus of government financing needs) and trade-off opportunities relative to other assets. All these arguments plead in favor of using shares, as they will only capture the factors impacting differently domestic and foreign demand for domestic debt securities.

There are two types of sources of variation in home bias in our SVAR: fundamental shocks and expectations shocks, both domestic and global. The fundamental fiscal shock that we consider is a debt to GDP ratio shock (debt), as the debt to GDP ratio (in \%) is widely used for assessing the fiscal fundamental situation of a country (see e.g. De Grauwe and Ji (2013)) and has the merit of being available for all countries over our whole period of study. A higher debt to GDP ratio means that the debt burden relative to the size of the economy is higher and is thus expected to increase the probability of sovereign default, and therefore to raise home bias in sovereign debt, due to diverging incentives to buy the debt for domestic and foreign investors. In addition, we include two distinct expectations variables in the SVAR. First, we consider global, non-European-specific expectations, as proxied by the VIX (vix) in \%, which represents the near term volatility conveyed by stock index option prices (S\&P 500 index) and is widely used as a proxy for global risk aversion. Indeed, Favero and Giavazzi (2008), among others, have shown that the Eurozone economies are deeply affected by global conditions and Andritzky (2012) argues that the strong increase in global risk aversion following the subprime financial crisis may have pushed foreign investors to retract from advanced financial markets. In addition, the inclusion of the VIX variable in the SVAR enables to control for time variations related to the global crisis period, as it proxies uncertainty and global liquidity (Matsumoto, 2015). Second, we consider country-specific expectations of sovereign default. We proxy a country-specific expectations of default shock with a 10-year sovereign bond yield spread shock (spread), with the fundamental control variables and the global expectations variable remaining constant (shocks are 
indeed orthogonalized). The variable spread is calculated as the difference (in \%) between the US yield and the German yield for Germany and as the difference between the German yield and each country yield for all other countries in the sample. It is the most widely used measure for countryspecific expectations of sovereign default (see e.g. De Grauwe and Ji (2013)).

Additionally, we include the quarter-on-quarter change of seasonally adjusted GDP at constant prices (gdpgt) as a further domestic fundamental control variable (Schumacher, 2014). Including the growth rate in the SVAR also allows to test the theoretical prediction according to which an increased home bias negatively affects growth (Broner et al., 2014). ${ }^{7}$

Data on VIX comes from the CBOE and data on 10-year government bond yields, seasonally adjusted quarter-on-quarter change in real GDP and debt to GDP ratio were extracted from the Eurostat and OECD databases. The reduced form of the panel vector autoregressive model with $q$ lags $\operatorname{VAR}(q)$ is:

$$
Y_{i, t}=\sum_{j=1}^{q} A_{j} Y_{i, t-j}+e_{i, t},
$$

where $Y_{i, t}$ is the vector of 5 endogenous variables for country $i$ and period $t, Y_{i, t-j}$ the vector of lagged variables, $A_{j}$ the $5 \times 5$ parameter matrix, and $e_{i, t}=b_{i}+b_{i, t}$, where $b_{i}$ is a vector of individual specific constants that vary with $i$, which controls for individual fixed effects, and $b_{i, t}$ is the disturbance term with $E\left(b_{i, t}\right)=0$. Its variance-covariance matrix $E\left(b_{i, t} b_{i, t}^{T}\right)=\Omega$ is unrestricted. ${ }^{8}$ Time fixed effects are controlled for by the VIX variable, which varies over time but not between countries, and which is expected to capture time-specific global expectations and global liquidity conditions.

The $\operatorname{VAR}(q)$ model can be rewritten using the lag operator $L:^{9}$

$$
A(L) Y_{i, t}=e_{i, t} .
$$

\footnotetext{
${ }^{7}$ Another variable of interest could be liquidity injections by the ECB, as they may have prompted home bias to increase by providing liquidity to domestic investors wishing to invest in domestic debt securities. At the same time, liquidity injections may have helped restoring confidence and thus limiting expectation shocks. However, liquidity injections by the ECB are still recent with the first long-term refinancing operations being conducted in April 2008 and most significant LTRO being implemented only from 2011 onwards, which makes it difficult to properly test for their impact.

${ }^{8}$ The notation.$^{T}$ refers to the transpose vector.

${ }^{9}$ Relying on the Akaike Information Criterion (AIC) and the Schwarz' Bayesian Information Criterion (BIC), we retained 1 lag in our estimation.
} 
Relying on the Wold theorem, the canonical VAR model can be reverted. Thus, we can rewrite the process in moving average infinite structural form:

$$
Y_{i, t}=\sum_{k=0}^{\infty} C_{k} e_{i, t-k}=C(L) e_{i, t}
$$

with $e_{i, t}$ representing the vector of canonical innovations. This allows to derive the impulse response functions and the forecast error variance decomposition. The structural Moving Average representation is then:

$$
Y_{i, t}=\sum_{k=0}^{\infty} \Theta_{k} \varepsilon_{i, t-k}=\Theta(L) \varepsilon_{i, t},
$$

where $\varepsilon_{i, t}=d_{i}+d_{i, t}$, and $b_{i, t}=P d_{i, t}$ (Beetsma et al. (2006), and Canova and Ciccarelli (2013)).

$P$ is a $5 \times 5$ invertible matrix. It needs to be estimated for identifying the structural shocks. The shortrun constraints consist in setting some elements of the matrix $P$ to zero. The $\Theta_{k}$ matrix represents the response functions of $Y_{i, t}$ to structural shocks $d_{i, t}$. Structural shocks are assumed to be uncorrelated and to have a unit variance: $E\left(d_{i, t} d_{i, t}^{T}\right)=I_{5}$. With $\Omega$ the variance-covariance matrix of the canonical innovations $b_{i, t}$, we have: $E\left(b_{i, t} b_{i, t}^{T}\right)=P E\left(d_{i, t} d_{i, t}^{T}\right) P^{T}=P P^{T}=\Omega$.

For the estimation of our panel SVAR, we rely on Bayesian inference, which is not affected by the presence of unit roots (Sims (1988), Sims and Uhlig (1991), and Uhlig (1994)). Consequently, first differencing the variables is not necessary, even though some of them are not stationary. Performing the econometric tests on the variables in levels then enables better interpretation regarding significance and sign of the results. As is standard in literature (Mackowiack (2007), and Kim and Roubini (2000)), we rely on the standard prior distributions of Sims and Zha (1998). They present several advantages. First, they are not flat, thus enabling to incorporate prior information. Second, they do not imply any restriction on the conditional mean of lagged variable coefficients. Nevertheless, beliefs about lagged variable coefficients are restricted to be Gaussian and uncorrelated across equations conditional on contemporaneous variable coefficients. However, they are allowed to be correlated differently in distinct equations.

We define $Y=\left(\begin{array}{c}h b \\ \text { spread } \\ d e b t \\ g d p g t \\ v i x\end{array}\right)$ the vector of endogenous variables, and $\varepsilon_{t}=\left(\begin{array}{c}\varepsilon_{h b} \\ \varepsilon_{\text {spread }} \\ \varepsilon_{\text {debt }} \\ \varepsilon_{\text {gdpgt }} \\ \varepsilon_{\text {ext }}\end{array}\right)$ the vector of 
structural shocks, where $\varepsilon_{h b}, \varepsilon_{\text {spread }}, \varepsilon_{d e b t}$, and $\varepsilon_{g d p g t}$ are four domestic shocks: respectively the home bias shock, the spread shock, the debt shock and the real supply shock, and $\varepsilon_{\text {ext }}$ represents the global financial shock.

The short-run restrictions We only impose short-run restrictions. We aim at identifying the 25 elements of the $P$ matrix. The $\Omega$ matrix is symmetric and the shocks have a one-unit variance. This implies that 15 orthogonalization and normalization constraints have already been imposed. Thus, it is necessary to determine the 10 remaining constraints by relying on the economic literature. First, we assume that global risk aversion is contemporaneously exogenous to domestic shocks in the Eurozone countries. Indeed, the VIX, as a proxy for global non-European financial conditions, is expected to affect the European financial markets in a first step and then to be potentially impacted by the impaired conditions in the European countries through a feedback effect only in a second step (Gonzalez-Hermosillo and Johnson, 2014). ${ }^{10}$ Second, as is standard in the literature, we assume that the real variables (GDP and debt to GDP ratio) react with a lag to financial disturbances (domestic and global: spreads and VIX) and to the composition of debt (hb) due to reaction delays (Kim (2005), Favero and Giavazzi (2008), Prieto et al. (2013), and Allegret et al. (2014)).

Therefore, given the ordering in the $Y$ matrix, the $P$ matrix of restrictions is defined as:

$$
P=\left(\begin{array}{ccccc}
1 & X & X & X & X \\
P_{21} & 1 & P_{23} & P_{24} & P_{25} \\
0 & 0 & 1 & P_{34} & 0 \\
0 & 0 & P_{43} & 1 & 0 \\
0 & 0 & 0 & 0 & 1
\end{array}\right)
$$

\subsection{Interpretation of results}

We focus first on the interpretation of the impulse response functions for the whole panel (six countries) depicted on Figure 4, which address the dynamics and impact of home bias. ${ }^{11}$ Our choice of a panel data analysis is motivated by the fact that we want to identify the common factors behind the increase in home bias for most of the countries in the sample. We want to establish a general transmis-

\footnotetext{
${ }^{10}$ Note that we impose the exogeneity of the VIX variable only in the first period. The VIX is allowed to respond to domestic shocks in the following periods. However, the results displayed below show that the VIX does not seem to significantly react to home bias and spread shocks in the Euro area in our sample. As for the debt and the gdp shocks, their contribution to the variation in the VIX is weak. Similarly, Favero and Giavazzi (2008) consider that the US economy behaves as a closed economy and is therefore not impacted by economic conditions in Eurozone countries, which justifies that they consider the US variables as the most exogenous ones with respect to Euro area variables shocks.

${ }^{11}$ As the data on home bias is available only over the period 2007-2014 for Portugal, it is not included in our panel tests but it is used in an individual test over the recent period (as it is available monthly) in order to provide additional and more refined results.
} 
sion mechanism between our variables of interest that would be relevant for the entire sample once individual heterogeneity is controlled for and that would allow for obtaining non-country-specific results regarding home bias. The distinct impulse response functions show the responses of domestic variables and of the global financial conditions indicator following each shock. They were generated using the Sims and Zha (1999) Bayesian Monte-Carlo integration method. The standard errors associated with a one standard error deviation shock were calculated with the same method. ${ }^{12}$ The associated forecast error variance decompositions, which allow for a comparison of the relative importance of each shock in explaining the dynamics of the distinct variables, are displayed in Appendix C. Shocks are named in columns and responses of variables to shocks are displayed in rows.
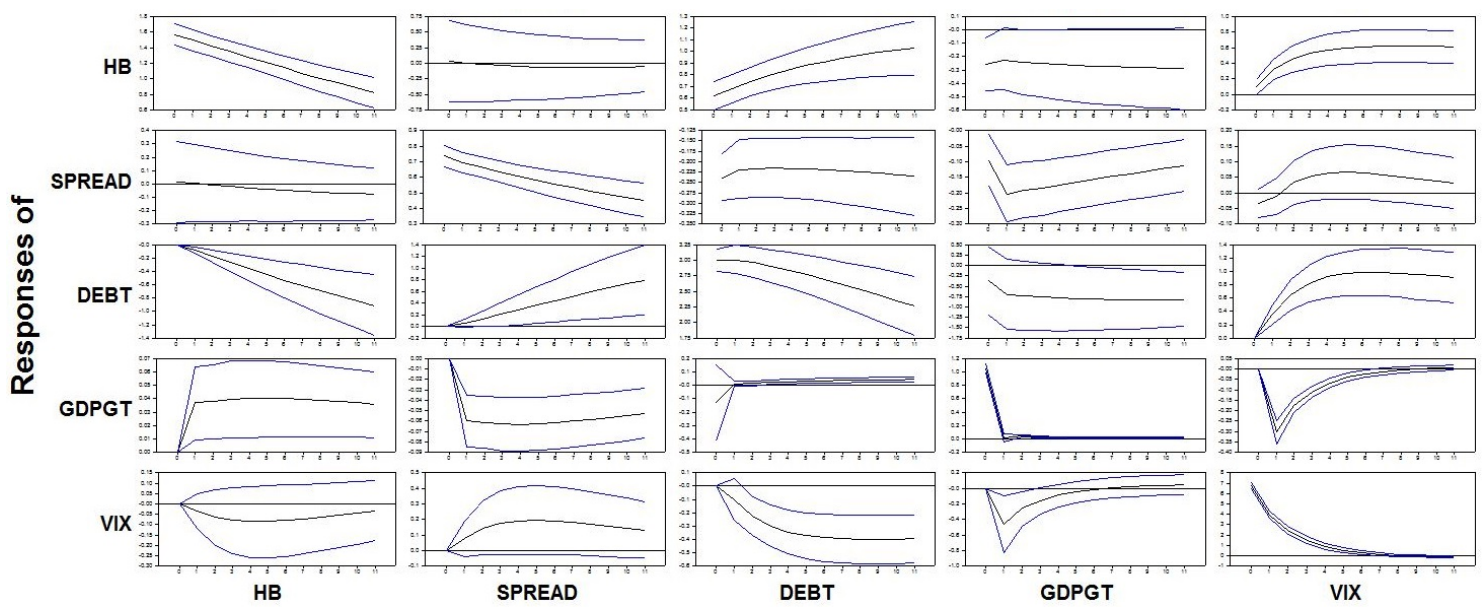

Figure 4: Panel impulse response functions - Whole sample

First, Figure 4 shows that a debt to GDP ratio shock triggers a positive significant response in home bias. Similarly, Schmidt and Zwick (2015) and Brutti and Sauré (2015) show that country-specific risk factors are crucial in explaining extreme capital flows in the Euro area. As this result is significant at the panel level, it suggests that debt shocks impact positively home bias both in countries where its recent increase was driven by a decrease in foreign volume and an increase in domestic volume and in countries where it was driven by domestic volume increasing faster than foreign volume, what is also confirmed by invididual tests presented below. This is consistent with our interpretation that home bias increases following probability of default shocks, which provides less incentives to foreign creditors to buy domestic debt securities relative to domestic creditors - the mechanism is developed

\footnotetext{
${ }^{12}$ The confidence interval calculated from the Sims and Zha (1999) procedure outperforms other procedures for short horizons (Kilian and Chang, 2000). Error bands correspond to the $16 \%$ and $84 \%$ quartiles. Results are significant if the confidence interval does not include the 0 axis.
} 
in the theoretical section -, and which can translate both into an increase in domestic holdings simultaneous with a decrease in foreign holdings and into foreign holdings increasing less than domestic volumes, depending on the size of the shock.

Second, Figure 4 shows that a positive GDP shock contemporaneously generates a decrease in home bias but is not persistent. An unexpected exogenous increase in GDP provides a comforting signal on the fundamental economic situation of a particular country, which causes foreign investors to increase their participation on the sovereign debt market of this country. Therefore, home bias seems to react to sudden impaired domestic fundamentals. This deepens the differences between incentives for domestic and foreign creditors to invest in domestic sovereign debt, as emphasized by previous literature, notably Battistini et al. (2014).

Third, Figure 4 depicts an increase in home bias in response to a positive VIX shock. This result is intuitive: when global risk aversion unexpectedly increases, foreign investors may become more cautious and invest less in public debt abroad, particularly the most risky one, as highlighted by Andritzky (2012).

Regarding the relative importance of the impact of each shock on home bias, the variance decomposition (Appendix C, Table 1) reveals that the fundamental shock explains $11.64 \%$ of the variation in home bias 1 quarter after the shock and 26.18\% 12 quarters after the shock. The fiscal fundamental shock thus has a significant and persistent effect on home bias. After the fiscal fundamental shock, the GDP shock is the main contemporaneous driver of the increase in home bias, explaining $2.15 \%$ of the variation in home bias 1 quarter after its occurrence (against $0.35 \%$ for the VIX shock). However, 12 quarters after its occurrence, the VIX shock explains 10.06\% of the variation in home bias (whereas the GDP shock no longer has a significant impact). Finally, in the panel tests on the sample of six countries, home bias does not significantly react to spread shocks. However, additional tests reveal that, as expected following Broner et al. (2014) and Brutti and Sauré (2015), in some countries, home bias does respond positively and significantly to spread shocks, as is made clear below.

To fully exploit the results of our SVAR estimation, another conclusion that we can draw is the impact of a home bias shock on the dynamics of the growth rate. Indeed, one significant advantage of the SVAR is that it enables to distinguish between bi-directional transmission mechanisms. The theoretical literature emphasizes a possibly destabilizing causal effect of increased home bias on the growth rate through crowding-out effects. Indeed, Broner et al. (2014) show that, due to financial frictions, increasing incentives for domestic investors to buy public debt when its return rises disrupt domestic productive investment, which in turn reduces growth. Another possible effect of increasing 
home bias on the growth rate may be related to its potentially negative impact on domestic banks' credit supply due to banks' exposure to sovereign risk, eventually reducing investment and growth (Acharya et al., 2012). Nevertheless, we cannot find empirical evidence of a negative transmission mechanism to the growth rate: the latter actually even responds slightly positively to home bias shocks in our sample. Nevertheless, the relative impact of the home bias shock on the growth rate is rather weak (the variance decomposition reveals that the home bias shock explains a small $0.12 \%$ of the variation in the quarter-on-quarter growth rate 2 quarters after its occurrence, against $7.06 \%$ for the VIX shock for instance). One possible explanation for this result could be that the negative impact of home bias on the growth rate is likely to be very indirect and not to occur in the short run. In particular, Cantero-Saiz et al. (2014) show that in periods of easy monetary policy, no systematic linear relationship between sovereign risk and credit supply exists in Europe. Moreover, our empirical result may relativize the extent of the financial frictions and the prominence of residents in domestic productive investment assumed in the theoretical literature (see Broner et al. (2014)). Our results still hold when we substitute the quarter-on-quarter change in growth rate with the year-on-year change in growth rate. Consequently, because we cannot find empirical grounds to plead for a direct negative effect of increasing home bias on the growth rate in our sample, we choose not to include it in our theoretical model of Section 3. Finally, regarding the impact of home bias on the other variables, a home bias shock does not significantly affect spreads - suggesting that markets do not incorporate the home bias variable in risk assessment, possibly due to data availability timing -, and generates a negative response of debt. While the latter result may sound surprising, it disappears when tests are performed over two sub-periods as we shall see below.

\subsection{Additional tests}

To refine our panel analysis, we conduct additional tests.

In a first step, following De Grauwe and Ji (2013), we perform the empirical tests for the whole sample on two sub-periods, 2002-2007 and 2008-2014, in order to account for possible differences in the post-crisis period. ${ }^{13}$ Even if the time periods are thus short, impulse response functions presented on Figures 9 and 10 reported in Appendix B and variance decompositions reported in Tables 2 and 3 in Appendix $\mathrm{C}$ allow to provide some information on differences between the two periods. Results are however mostly in line with the whole sample analysis. Home bias in sovereign debt still responds

\footnotetext{
${ }^{13}$ We performed a Chow test in our SVAR in order to test for the presence of a structural break around the year 2008, as in De Grauwe and Ji (2013). The Chi-2 statistic that we obtain is 97.5 (with 60 degrees of freedeom), with an associated P-value of 0.002 , which justifies that we conduct a separate analysis.
} 
positively and significantly to debt to GDP ratio shocks in both sub-samples, even though with some lag in the last one. Similarly, home bias still responds negatively to GDP shocks in both sub-periods. The GDP shock thus explains $6.42 \%$ of the home bias variation 12 quarters after its occurrence in the second sub-period, which is even higher than the share explained by the debt shock. Consistently with the whole sample estimation results, home bias shocks do not affect the spreads in both subsamples. They do not affect the debt to GDP ratio neither nor the GDP growth rate. However, spread shocks have a significant positive impact (with some lag) in the first sub-period, explaining $4.65 \%$ of the variation in home bias 4 quarters after its occurrence and $11.85 \% 12$ quarters after its occurrence. Finally, VIX shocks do not have a significant impact on home bias in the first sub-period and they have a significant impact on home bias after 7 quarters only in the second sub-period, which suggests that VIX shocks are showed to play a role in the largest sample because more variation in global conditions is observed over the whole period. This decomposition into two sub-periods thus allows us to provide more refined results regarding the differences which exist between the pre- and the post-crisis periods. However, as the results are roughly consistent with the whole period estimation results and because we are not directly interested in the estimated parameters of our VAR, we focus on the whole period in the following tests, which allows to rely on larger data.

In a second step, as our sample includes both debtor and creditor countries, we also perform the tests on a smaller sample restricted to the debtor countries. We thus conduct the same analysis as for the whole period, but on a panel including four countries: Greece, Ireland, Italy, and Spain, that is the GIIPS countries for which we have data over the whole period. The focus on those countries avoids too much sample heterogeneity. Impulse response functions depicted on Figure 11 in Appendix B exhibit very similar patterns as those of Figure 4 involving the whole sample except that the impact of a GDP shock on home bias is even less persistent (see also the variance decomposition available in Table 4 reported in Appendix C).

Third, in order to emphasize some country-specific relationships between our variables of interest and refine our results, we exploit the fact that some national central banks have started to disclose monthly data on resident and foreign holdings of domestic sovereign debt in order to perform individual tests, as it allows us to rely on larger individual time series. When monthly data on home bias in sovereign debt securities was available, we performed additional country-specific tests over the period 2002-2014 (for Ireland, Italy and Spain) and over the period 2007-2014 for Portugal (due to data availability). This analysis allows to specify the results, which are expected to display some country-specific features. As GDP is not available monthly, we use the month-on-month change (\%) 
in industrial production as a proxy. As for the debt to GDP ratio, we substitute it by the ratio of the volume of the proxy for total debt used in the calculation of home bias (as it is then available monthly) over the yearly GDP (\%), that is, government debt securities. It appears that in Ireland, fundamental debt shocks explain a very large part of the variation in home bias (Figure 12 in Appendix B). Indeed, the variance decomposition (Table 5 in Appendix C) reveals that the debt shock explains $34.93 \%$ of the variation in home bias 12 quarters after its occurrence. By contrast, the individual tests allow to see that spread shocks do have a significant positive impact on the dynamics of home bias after some lag in Italy, Spain and Portugal and even that they explain a larger variation in home bias relative to fundamental shocks (Figures 13, 14, and 15 in Appendix B) and have a persistent effect. ${ }^{14}$ This is particularly true for Italy, for which the variance decomposition (Table 6 in Appendix C) shows that the spread shock explains more than $6 \%$ of the variation in home bias 4 quarters after the shock (against $0.64 \%$ for the debt shock) and more than $27 \% 12$ quarters after the shock (against $1.79 \%$ for the debt shock). In Portugal (Table 8 in Appendix C), the expectations shock explains almost 35\% of the variation in home bias 12 quarters after the shock (against 11.27\% in Spain (Table 7 in Appendix C)). Interestingly, it appears that expectation shocks impact the variation in home bias in countries which were identified as being particularly prone to self-fulfilling dynamics in the Eurozone sovereign debt crisis (De Grauwe and Ji, 2013). The fact that home bias positively responds to spread shocks is in accordance with Broner et al. (2014) (in which the marginal buyer of sovereign bonds becomes a domestic one following a sovereign bond return shock) and with the empirical investigation of Andritzky (2012). This shock can affect home bias dynamics through various intermediary channels. Following Brutti and Sauré (2015), our interpretation of this effect is that the transmission channel between the expectations shock and home bias dynamics relates to the increase in the expected probability of default triggered by more pessimistic expectations (the so-called self-fulfilling effect), which provides more incentives for domestic investors to invest in domestic sovereign debt relative to foreign ones. In addition, the individual tests provide robustness checks regarding the effect of home bias shocks on the growth rate: the growth rate is not found to respond negatively to home bias shocks in any of the 4 countries for which monthly data is available. Note that this result holds both in countries where home bias in sovereign debt increased due to an increase in domestic volume and a decrease in foreign volume of domestic debt securities and in countries where home bias rose due to an increase

\footnotetext{
${ }^{14}$ Note that spread shocks also have a significant impact on the dynamics of home bias in the panel tests as soon as Greece, which displays some specific features due to partial default on its debt in March 2012, is removed from the sample. We interpret the sovereign bond spread shock as an expectation shock because it represents a one standard error deviation in the risk premium, with all of the other endogenous variables of the empirical model - particularly the debt variable - remaining constant.
} 
in both volumes, with the domestic volume increasing faster.

To sum-up, additional tests confirm that two shocks significantly explain variations in home bias - at least in some countries of our sample: the debt shock and the expectation (spread) shock. In addition, the growth rate shock also plays a significant role, in particular in the most recent period. All those shocks are domestic shocks, which play a major role in comparison to the external shock.

\subsection{Robustness checks}

We now provide some robustness checks, by testing the sensitivity of our results to alternative identification strategies in our panel SVAR. As we relied on short-run restrictions, we test the robustness of our results to three distinct triangular Cholesky decompositions of the $P$ matrix. We retained those three distinct decompositions so that we still incorporate restrictions consistent with economic theory in choosing the ordering of the variables (namely that real variables do not react contemporaneously to financial variables and that the VIX variable is the most exogenous variable among the three financial variables), but we test alternative ordering between real variables on the one hand and between financial variables on the other hand. The first Cholesky decomposition $C_{1}$, the second Cholesky decomposition $C_{2}$ and the third Cholesky decomposition $C_{3}$ that we investigate are based on the following variables ordering (from the most exogenous one to the least exogenous one): $C_{1}=\left(\begin{array}{c}\text { debt } \\ g d p \\ \text { vix } \\ \text { spread } \\ h b\end{array}\right), C_{2}=\left(\begin{array}{c}g d p \\ d e b t \\ v i x \\ \text { spread } \\ h b\end{array}\right)$, and $C_{3}=\left(\begin{array}{c}\text { debt } \\ g d p \\ v i x \\ h b \\ \text { spread }\end{array}\right)$.

Results for the whole sample tests are displayed in Figures 16, 17, and 18 reported in Appendix B and Tables 9, 10, and 11 reported in Appendix C. ${ }^{15}$ It appears that the results are similar to those obtained with the short-run restrictions. One slight difference is that spread responds negatively to home bias shocks with the first and the second Cholesky decomposition (in which spreads are assumed to be more exogenous than home bias), but this effect is very small relative to that of other shocks, as attested by the variance decomposition (Tables 9 and 10). It however tends to suggest that if an increase in home bias has any impact on expectations of default, it is a stabilizing one.

\footnotetext{
${ }^{15}$ We performed all additional tests under the three alternative identification strategies. Overall, results are robust to alternative identification schemes and are available upon request.
} 
Now that we have identified the most important sources of exogenous variation in home bias in our empirical model, we examine their impact on the equilibrium of a simple model of sovereign debt crisis in which home bias affects the strategic decision of national governments regarding sovereign default. This allows us to formalize our interpretation of the transmission mechanism between exogenous variations in fundamentals or expectations and home bias and to characterize the conditions under which an increase in home bias is associated with sovereign default. As the strategic decision of the government, depending on home bias, is hardly observable, and the impact of home bias on default cannot be properly tested in the Eurozone due to specific features of the recent sovereign debt crisis and the absence of a number of default episodes, relying on a stylized model allows to formalize and to sum-up in a concise way a simple prediction on the factors that play a role in determining the consequences of the increase in home bias for debt sustainability.

\section{A simple model of debt crisis with endogenous home bias}

We now propose a stylized model of sovereign debt crisis in a monetary union, the assumptions of which are supported by our empirical results. It aims at replicating the recent rise in home bias associated with an increase in sovereign bond yields and at characterizing its consequences for the government's decision to default.

\subsection{The sequential game}

Our setting is a two-period strategic game involving three different players: domestic investors, foreign investors and the government.

The investors' decision In period 1, the government aims at rolling over an exogenous amount of one-period maturity debt $d_{1}$ on the primary sovereign bonds market. Each group of investors (the group of domestic creditors and the group of foreign ones) consists of a continuum of identical agents over the interval [0;1]. All individual investors have logarithmic utility and the same initial endowment $W_{1}$ at the beginning of period 1. In period 1, each individual investor - be it domestic or foreign - chooses the level of his current consumption $C_{1}$. He allocates the remaining part of his initial wealth $W_{1}-C_{1}$ between risky sovereign bonds, which yield an uncertain return determined endogenously on the sovereign bonds market and which is paid only in the absence of sovereign default, and a risk-free world asset which yields a constant certain exogenous return. A worldwide 
random macroeconomic shock $X$ (with density probability $f$ ) affecting the government's fiscal decision (a higher realization $\tilde{x}$ of the shock positively affects the government's solvency) occurs at the beginning of period 2. As they do not know the realization of the shock when they make their decision in period 1, investors cannot know with certainty whether the outcome will be default or not. Therefore, they make their decision based on the expected probability of default in period $1, p^{e}$. The timeline of the game is displayed in Figure $5{ }^{16}$

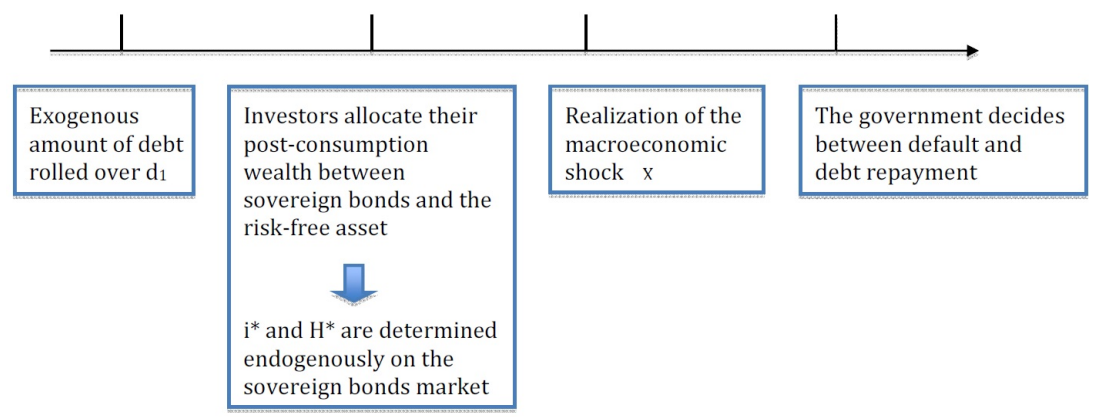

Figure 5: Timeline of the sequential game

The maximization programme of an individual investor in each group is the following (with $j=$ $(D, F)$ a general subscript, the subscript $D$ referring to domestic investors, the subscript $F$ to foreign ones):

$$
\max _{C_{1, j}, \omega_{j}} E_{1}\left[U\left(C_{1, j}, C_{2, j}\right)\right]=\max _{C_{1, j}, \omega_{j}} \ln \left(C_{1, j}\right)+\beta E_{1}\left[\ln \left(C_{2, j}\right)\right]
$$

s.t.

$$
\begin{gathered}
C_{1, j}+\frac{E_{1}\left[C_{2, j}\right]}{E_{1}\left[R_{T, j}\right]} \leq W_{1}, \\
E_{1}\left[R_{T, j}\right]=\left(1-\omega_{j}\right) R_{f}+\omega_{j} E_{1}\left[R_{j}\right], \\
0 \leq \omega_{j} \leq 1,
\end{gathered}
$$

where $\omega_{j}$ is the share of post-consumption wealth $\left(W_{1}-C_{1, j}\right)$ invested in domestic sovereign bonds (with $1-\omega_{j}$ the share invested in the risk-free asset), $\beta$ is the discount factor, $R_{T, j}$ is the total amount

\footnotetext{
${ }^{16}$ After the government makes its decision regarding default, the monetary policy authority - in the Eurozone, the ECB - can take action in order to avoid a sovereign default. Indeed, it can affect the government's political costs (notably, the cost of default), grant rescue loans with preferential conditions, buy government debt at lower interest rates on the secondary market, and refinance banks that are holding sovereign bonds. In addition, the ECB can affect ex ante expectations, notably through liquidity injections and commitment or announcement that it will intervene to help countries facing difficulties. Nevertheless, endogenizing the ECB's strategic decision is beyond the scope of this paper as it is unlikely to be affected by home bias.
} 
by which the portfolio-invested wealth is multiplied (thus including the repayment of the principal and the return paid on both types of assets), $R_{f}=1+r_{f}$ with $r_{f}$ the constant certain exogenous return on the risk-free world asset and $R_{j}$ is the amount paid to investors on sovereign bonds including both the implicit endogenous return on bonds and the repayment of the principal (when $j=D$, it corresponds to the amount for domestic creditors and when $j=F$ to the amount for foreign creditors). For a given nominal equilibrium interest rate $i^{*}\left(p^{e}\right)$ on domestic sovereign bonds depending on the expected probability of default $p^{e}$, as will be made clear below, and a given home bias in sovereign debt $H^{*}$ in equilibrium, the expected amount paid to domestic creditors on their investment in sovereign bonds $E_{1}\left[R_{D}^{*}\right]$ writes:

$$
E_{1}\left[R_{D}^{*}\right]=\left(1+i_{D}^{*}\right)\left(1-p^{e}\right)+0 \cdot p^{e}=\left(1+i_{D}^{*}\right)\left(1-p^{e}\right)
$$

and the expected amount paid to foreign creditors $E_{1}\left[R_{F}^{*}\right]$ writes:

$$
E_{1}\left[R_{F}^{*}\right]=\left(1+i_{F}^{*}\right)\left(1-p^{e}\right)
$$

where $i_{D}^{*}$ is the expected implicit return on domestic sovereign bonds for domestic creditors in equilibrium and $i_{F}^{*}$ is the expected implicit return for foreign creditors. When sovereign default occurs (with expected probability $p^{e}$ ), sovereign bonds yield a null return and the principal is not recovered by the creditors. When no sovereign default occurs (with expected probability $1-p^{e}$ ), the creditors recover the principal $\left(W_{1}-C_{1, j}\right) \omega_{j}$ and the implicit equilibrium return $i_{j}^{*}$ on the principal. The implicit equilibrium return for domestic investors $i_{D}^{*}$ differs from the implicit equilibrium return for foreign investors $i_{F}^{*}$. This results from some additional costs (for foreigners) or additional benefits (for domestic creditors) of investing in domestic sovereign bonds which are added to the nominal equilibrium interest rate on bonds $i^{*}\left(p^{e}\right)$ such that $i_{F}^{*} \leqslant i_{D}^{*}$. These additional costs and benefits differ all the more so in the midst of a stressful episode on the sovereign debt market. Indeed, as emphasized in the empirical literature, in the context of the Eurozone debt crisis, incentives to invest in the sovereign debt of the most fragile economies have decreased for foreign investors and increased (or at least decreased less) for domestic ones. Thus, Battistini et al. (2014) (p. 205) identified several types of increasing incentives for residents to invest in their own sovereign debt in fragile economies of the Eurozone. ${ }^{17}$

\footnotetext{
${ }^{17}$ The first one is the pressure government can exert on domestic banks to have them buy public debt - financial repression in the words of Reinhart and Sbrancia (2015). Moral suasion in the recent Eurozone debt crisis was thoroughly documented by Van Riet (2014). Investing in domestic sovereign bonds thus saves the cost of not
} 
Therefore, $i_{D}^{*}$ and $i_{F}^{*}$ can be rewritten as functions $i_{D}\left(i_{+}^{*}\left(p_{+}^{e}\right), p_{+}^{e}\right)$ and $i_{F}\left(i^{*}\left(p_{+}^{e}\right), p_{-}^{e}\right)$ of the expected probability of default $p^{e}$ and of the equilibrium nominal return on sovereign debt $i^{*}\left(p^{e}\right)$.

The equilibrium interest rate on domestic sovereign bonds $i^{*}\left(p^{e}\right)$ is the interest rate for which market clears, that is to say the interest rate for which total demand for domestic sovereign bonds $Q_{T}\left(i, p^{e}\right)$ equals the exogenous supply amount of domestic sovereign debt $d_{1}$ :

$$
Q_{T}\left(i^{*}\left(p^{e}\right), p^{e}\right)=d_{1}
$$

By definition, equilibrium home bias is the share of domestic debt held by domestic investors in the point where market clears:

$$
H^{*}=H\left(i^{*}\left(p^{e}\right), p^{e}\right)=\frac{Q_{D}^{*}}{Q_{D}^{*}+Q_{F}^{*}}=\frac{\omega_{D}^{*}}{\omega_{D}^{*}+\omega_{F}^{*}}=\frac{\omega_{D}^{*}\left(W_{1}-C_{1}^{*}\right)}{d_{1}} .
$$

The government's decision In period 2, the government observes the aggregate decision of all creditors $\left(i^{*}\left(p^{e}\right), H^{*}\right)$ and the realization of the macroeconomic shock $\tilde{x}$ which occurs at the beginning of period 2. It then decides between paying back the debt (which in period 2 includes interest rate payments: $\left.d_{2}=d_{1}\left(1+i^{*}\left(p^{e}\right)\right)\right)$ or defaulting on its full debt. ${ }^{18}$ As in Gennaioli et al. (2014) and Mengus (2014), the government is non-discriminatory regarding default in our model. ${ }^{19}$

To make its decision regarding fiscal policy in period 2 , the government strategically compares the cost of debt repayment $L_{f}$ with the cost of full default $L_{d}$, and chooses the least costly option. Thus, the optimizing government focuses on minimizing the economic and political costs of its fiscal policy. The loss function in case of default $L_{d}$ is related to the economic cost of a sovereign default for the domestic economy and to the political and economic cost of creditors opposition to default. ${ }^{20}$

complying with government's pressure. The second one is that undercapitalized banks, that are mostly located in peripheral countries, can choose to engage in 'carry-trades' by going long on more risky public debt and short on less risky one (see also Gennaioli et al. (2014)). The third one is related to a possible exit from the Eurozone, in which domestic investors would have a comparative advantage, as sovereign debt would be redenominated in national currency, what would be costly for foreign creditors. In addition, expectations of potential compensations of residents following a default (Mengus (2014), and Brutti and Sauré (2015)) can provide incentives for domestic purchases of debt. The first two reasons can only explain why banks have increased their exposure to domestic sovereign debt while the last two also apply to non-bank domestic investors.

${ }^{18}$ We focus on the binary alternative between full repayment and full default without taking into account the possibility of a partial haircut on debt. Nevertheless, the mechanism and results of the model would be similar when allowing for a haircut.

${ }^{19}$ This can be justified by trading on the secondary market (or by the one-period maturity of debt in our simple case), portfolios' unobservability and the monetary union that renders a selective default very unlikely. Gennaioli et al. (2014) provide empirical results supporting the non-discriminatory assumption. See also Panizza et al. (2009).

${ }^{20}$ The specificity of such loss functions in a monetary union is that national governments do not control monetary policy and thus cannot monetize debt, which reinforces the impact of the latter on the government's decision. 
Both the cost of debt repayment and the cost of default increase in the debt:

$$
\frac{\partial L_{d}}{\partial d_{1}}>0, \frac{\partial L_{f}}{\partial d_{1}}>0, \quad \text { with } \quad \frac{\partial L_{f}}{\partial d_{1}}>\frac{\partial L_{d}}{\partial d_{1}}
$$

as the probability of default increases in the debt.

In addition,

$$
\frac{\partial L_{d}}{\partial \tilde{x}}>0, \frac{\partial L_{f}}{\partial \tilde{x}}<0
$$

as a higher realization of the $X$ shock positively affects the government's solvency.

Both loss functions increase in the market interest rate on sovereign bonds $i^{*}\left(p^{e}\right)$ as it raises debt service, and therefore raises debt in period 2. The loss function in case of default $L_{d}$ increases more, as the probability of default increases when debt service rises. Home bias in equilibrium $H^{*}$ raises the cost of default as it raises the impact of a sovereign default for the domestic economy (Mengus, 2014) by increasing the domestic share of debt defaulted on, along with the domestic volume of debt defaulted on as soon as the debt volume remains constant or increases. ${ }^{21}$

Finally, in period 1, before the realization of the macroeconomic shock, the true probability of default $p^{*}$ (the probability that $L_{f}>L_{d}$ ) is the probability of default averaged over the whole distribution of the shocks for a given amount of debt and given aggregate outcomes: ${ }^{22}$

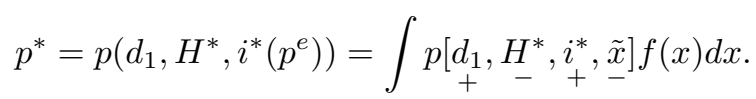

As agents are assumed to hold rational expectations, in equilibrium, $p^{e}=p^{*}$, such that the expected probability of default is in fine validated.

We now solve for the subgame perfect Nash equilibria of the model.

\subsection{Characterization of the subgame perfect Nash equilibria}

Investors' best response under uncertainty on the ex post outcome In order to characterize the optimal decision for an individual investor such that he does not have incentives to deviate from

This specificity also renders the Eurozone countries more prone to self-fulfilling crises due to liquidity shortages converting into solvency crises (De Grauwe and Ji (2013), and Corsetti and Dedola (2013)).

${ }^{21}$ Acharya et al. (2014) and Gennaioli et al. (2014) relate the internal domestic cost of default to domestic banks' holdings of domestic sovereign bonds. Gennaioli et al. (2014) provide empirical evidence that the larger the exposure of domestic banks to sovereign risk, the more costly the default for the domestic economy through its ex post impact on private credit.

${ }^{22} p$ in the following equation is a function, as for given values of the model's parameters, of the endogenous variables in equilibrium, and of the shock, it takes one and only one value. 
equilibrium, the action of all other players are taken as given. This means that both the strategy of all other investors (in the same group and in the other group) - and then the aggregate outcomes resulting from these individual actions $i^{*}\left(p^{e}\right)$ and $H^{*}$ - and the strategy of the government prior to the realization of the shock (captured by the expected probability of default $p^{e}$ ) are taken as given in order to derive the individual investor's best response.

The first order conditions for each individual investor yield:

$$
\begin{gathered}
C_{1}^{*}=\frac{1}{1+\beta} W_{1}, \\
\omega_{D}^{*}=\max \left[\min \left(\frac{i_{D}\left(i^{*}\left(p^{e}\right), p^{e}\right)-r_{f}-p^{e}\left(1+i_{D}\left(i^{*}\left(p^{e}\right), p^{e}\right)\right)}{i_{D}\left(i^{*}\left(p^{e}\right), p^{e}\right)-r_{f}}, 1\right), 0\right], \\
\omega_{F}^{*}=\max \left[\min \left(\frac{i_{F}\left(i^{*}\left(p^{e}\right), p^{e}\right)-r_{f}-p^{e}\left(1+i_{F}\left(i^{*}\left(p^{e}\right), p^{e}\right)\right)}{i_{F}\left(i^{*}\left(p^{e}\right), p^{e}\right)-r_{f}}, 1\right), 0\right] .
\end{gathered}
$$

This determines the aggregate outcomes $H^{*}$ and $i^{*}\left(p^{e}\right)$ for a given expected probability of default $p^{e}$. Figure 6 illustrates the endogenous home bias.

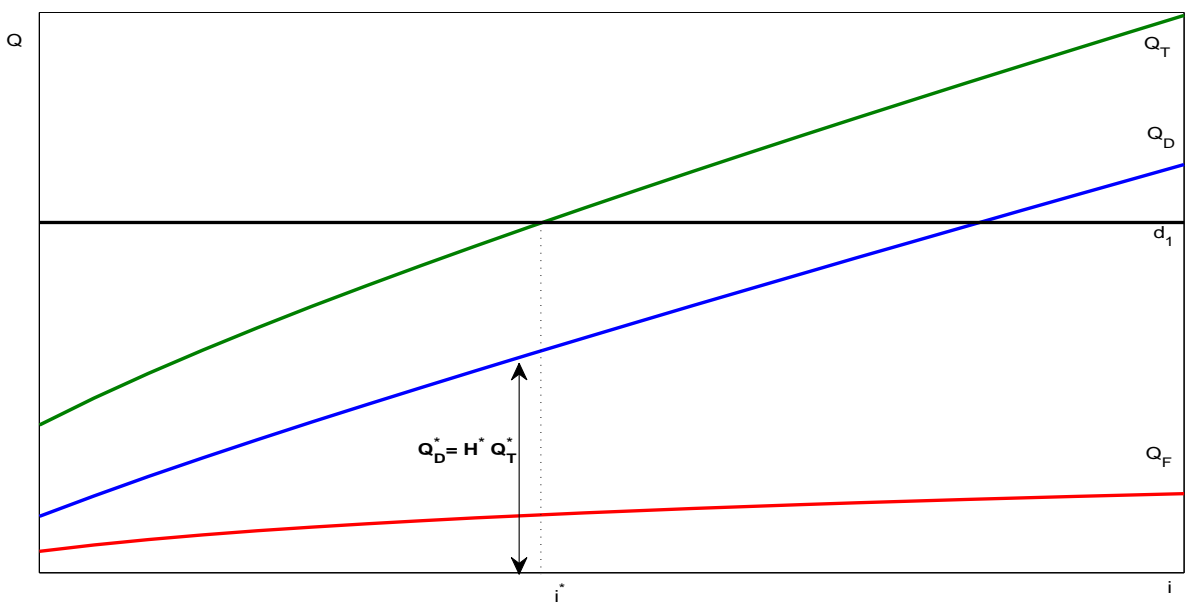

Figure 6: Endogenous home bias

The government's best response At the time the government plays its optimal strategy (at the end of period 2), if: $L_{f}\left(d_{1}, H^{*}, i^{*}\left(p^{e}\right), \tilde{x}\right)-L_{d}\left(d_{1}, H^{*}, i^{*}\left(p^{e}\right), \tilde{x}\right)<0$, the government's best response 
to creditors' action is to pay back the debt, as it is less costly than defaulting on debt.

If: $L_{f}\left(d_{1}, H^{*}, i^{*}\left(p^{e}\right), \tilde{x}\right)-L_{d}\left(d_{1}, H^{*}, i^{*}\left(p^{e}\right), \tilde{x}\right)>0$, the government's best response is to default.

As the endogenous aggregate outcome of investors' individual optimal decisions $H^{*}$ and $i^{*}\left(p^{e}\right)$ affect the government's decision, multiple equilibria may arise in the model depending on investors' expectations if, and only if, distinct expectations are validated in equilibrium for the same $d_{1}$. Indeed, distinct expected probabilities of default lead to distinct individual decisions and thus to distinct aggregate outcomes, which in turn affect the ex ante probability of default. In particular, for a given $d_{1}$, if investors expect the probability of default to be null $\left(p^{e}=0\right)$, this yields $H^{*}=\frac{1}{2}$ and $i^{*}(0)=r_{f}$. These beliefs hold in equilibrium if, and only if, for $H^{*}=\frac{1}{2}$ and $i^{*}(0)=r_{f}$, it is indeed optimal for the government not to default, whatever the realization of the shock (that is, if and only if, $p\left(d_{1}, \frac{1}{2}, 0\right)=0$ ). If investors expect the probability of default to be 1, demand for domestic sovereign bonds is null and this pushes the government into a roll-over crisis in period 1 . These beliefs are validated for all values of $d_{1}$. Eventually, if creditors expect the probability of default to be $0<p^{e}<1$, this yields $H^{*}>\frac{1}{2}$ and $i^{*}\left(p^{e}\right)>r_{f} .{ }^{23}$ Therefore, this gives rise possibly to an infinity of equilibria for a given $d_{1}$, due to the continuum of shocks. Which equilibria arise for a given $d_{1}$ depends on the value of $d_{1}$ and on the government's loss functions. We now assess the impact of more pessimistic expectations and higher debt level on the model's equilibrium to replicate the increase in home bias and assess its potential consequences for sovereign debt crisis.

\subsection{Change in equilibrium following an exogenous change in expectations}

We consider an initial equilibrium and we assess the consequences on the creditors and the government's decisions of an exogenous change in expectations based on our prior empirical results.

Shift in investors' decision We first assess the conditions under which expectations becoming suddenly more pessimistic cause home bias in sovereign debt to increase for a given debt fundamental. We thus consider the impact of an exogenous marginal increase in the expected probability of default. Two cases allow to replicate the increase in home bias associated with an increasing market return on sovereign debt.

\footnotetext{
${ }^{23}$ Indeed, as $p^{e} \neq 0, \omega_{D}\left[i^{*}\left(p^{e}\right), p^{e}\right]-\omega_{F}^{*}\left[i^{*}\left(p^{e}\right), p^{e}\right]=\frac{\left(i_{D}\left[i^{*}\left(p^{e}\right), p^{e}\right]-i_{F}\left[i^{*}\left(p^{e}\right), p^{e}\right]\right) p^{e}\left(1+r_{f}\right)}{\left(i_{D}\left[i^{*}\left(p^{e}\right), p^{e}\right]-r_{f}\right)\left(i_{F}\left[i^{*}\left(p^{e}\right), p^{e}\right]-r_{f}\right)}>0$. As risk of default is then expected to be non-null, investors accept to buy the debt stock $d_{1}$ if and only if $i^{*}\left(p^{e}\right)>r_{f}$. It is indeed assumed that domestic post-consumption wealth $W_{1}-C_{1}^{*}$ is lower than the exogenous debt supply $d_{1}$, such that domestic creditors cannot buy all the debt stock.
} 
First, if expectations switch from an expected null probability of default to an expected probability of default of $0<p^{e^{2}}<1$, home bias increases, as it goes from $H^{*^{1}}=\frac{1}{2}$ to $H^{*^{2}}>\frac{1}{2}$ and so does the equilibrium return on sovereign debt, as it goes from $i^{*}(0)=r_{f}$ to $i^{*}\left(p^{e^{2}}\right)>r_{f}$. In this case, the increase in home bias is explained by the fact that creditors no longer expect the probability of a sovereign default to be null, which makes foreign and domestic demand for domestic debt securities no longer equal, due to diverging expected implicit returns when the probability of default differs from 0 . Domestic demand thus becomes higher than foreign demand for any return $i$, and in particular in equilibrium, as shown above, which ensures that $H^{*}>\frac{1}{2}$. However, this case arises for a given fiscal fundamental $d_{1}$ if and only if the expectation shock, which makes the expected probability of default go from 0 to $0<p^{e^{2}}<1$, is in fine validated following the endogenous change in aggregate decisions $i^{*}\left(p^{e^{2}}\right)$ and $H^{*}$, that is if and only if $p\left(d_{1}, H^{*^{2}}, i^{*}\left(p^{e^{2}}\right)\right)=p^{e^{2}}>0$ prior to the macroeconomic shock. Homogenous individual expectations are validated through their impact on aggregate decisions and thus on the government's decision. The endogenous increase in $i^{*}\left(p^{e}\right)$ following the expectation shock causes the probability of default to rise, whereas the increase in $H^{*}$ makes it decrease. Therefore, more pessimistic expectations are validated if and only if the positive impact of a higher $i^{*}\left(p^{e}\right)$ on the probability of default dominates that of a higher $H^{*}$.

Second, if the expected probability of default marginally increases from $0<p^{e^{1}}<1$ to an expected probability of default of $0<p^{e^{2}}<1$ for a given $d_{1}$, plausible conditions allow to replicate the increase in home bias associated with an increase in the market interest rate in equilibrium.

The market rate increases following a pessimistic expectations shock due to a decrease in total demand for sovereign bonds. Indeed, for a given $i$ and a given $0<p^{e}<1$, foreign demand writes:

$$
\omega_{F}\left[i, p^{e}\right]=\frac{i_{F}\left(i, p^{e}\right)-r_{f}-p^{e}\left(1+i_{F}\left(i, p^{e}\right)\right)}{i_{F}\left(i, p^{e}\right)-r_{f}}
$$

Therefore,

$$
\frac{\partial \omega_{F}}{\partial p^{e}}=\frac{\left(r_{f}-i_{F}\left(i, p^{e}\right)\right)\left(1+i_{F}\left(i, p^{e}\right)\right)+p^{e}\left(1+r_{f}\right) \frac{\partial i_{F}}{\partial p^{e}}\left(i, p^{e}\right)}{\left(i_{F}\left(i, p^{e}\right)-r_{f}\right)^{2}}<0 .
$$

as $\frac{\partial i_{F}}{\partial p^{e}}\left(i, p^{e}\right)<0$. Similarly,

$$
\frac{\partial \omega_{D}}{\partial p^{e}}=\frac{\left(r_{f}-i_{D}\left(i, p^{e}\right)\right)\left(1+i_{D}\left(i, p^{e}\right)\right)+p^{e}\left(1+r_{f}\right) \frac{\partial i_{D}}{\partial p^{e}}\left(i, p^{e}\right)}{\left(i_{D}\left(i, p^{e}\right)-r_{f}\right)^{2}}
$$


As the negative risk effect of an increasing expected probability of default on demand is assumed to dominate the positive return effect (due to higher additional benefits), that is:

$$
\left|\left(r_{f}-i_{D}\left(i, p^{e}\right)\right)\left(1+i_{D}\left(i, p^{e}\right)\right)\right|>p^{e}\left(1+r_{f}\right) \frac{\partial i_{D}}{\partial p^{e}}\left(i, p^{e}\right)
$$

domestic demand also decreases in the expected probability of default for a given $i$. Therefore, the market clearing interest rate $i^{*}\left(p^{e}\right)$ increases. ${ }^{24}$

As for the equilibrium home bias, according to the first order conditions, it writes:

$$
H^{*}=\frac{\left(\omega_{D}\left[i^{*}\left(p^{e}\right), p^{e}\right]\right) W_{1}}{d_{1}(1+\beta)}=\frac{i_{D}\left(i^{*}\left(p^{e}\right), p^{e}\right)-r_{f}-p^{e}\left(1+i_{D}\left(i^{*}\left(p^{e}\right), p^{e}\right)\right)}{i_{D}\left(i^{*}\left(p^{e}\right), p^{e}\right)-r_{f}} \frac{W_{1}}{d_{1}(1+\beta)}
$$

Therefore, a sufficient and necessary condition such that home bias rises following a marginal increase in the expected probability of default (obtained by differentiation with respect to $p^{e}$ ) is thus:

$$
s\left[i^{*}\left(p^{e}\right), p^{e}\right] \geq \frac{i_{D}\left(i^{*}\left(p^{e}\right), p^{e}\right)\left(i_{D}\left[i^{*}\left(p^{e}\right), p^{e}\right]-r_{f}+1\right)}{p^{e}\left(1+r_{f}\right)},
$$

with

$$
s\left[i^{*}\left(p^{e}\right), p^{e}\right]=i^{*^{\prime}}(p) \frac{\partial i_{D}}{\partial i}\left(i^{*}\left(p^{e}\right), p^{e}\right)+\frac{\partial i_{D}}{\partial p^{e}}\left(i^{*}\left(p^{e}\right), p^{e}\right)>0 .
$$

This term captures the variation in the expected implicit domestic return following the increase in the expected probability of default. It is positive as for domestic investors, an increased expected probability of default increases the implicit return due to both a return effect (represented by the term $\left.i^{*^{\prime}}(p) \frac{\partial i_{D}}{\partial i}\left(i^{*}\left(p^{e}\right), p^{e}\right)>0\right)$ and a risk effect (represented by the term $\left.\frac{\partial i_{D}}{\partial p^{e}}\left(i^{*}\left(p^{e}\right), p^{e}\right)\right)>0$ ): the higher equilibrium interest rate increases the implicit equilibrium return but the higher expected default probability also raises it, as it provides more incentives to invest in domestic debt for domestic creditors, as justified above. By contrast, for foreign investors, the return effect affects positively the foreign implicit return but the risk effect has a negative impact on the foreign implicit return (as $\left.\frac{\partial i_{F}}{\partial p^{e}}\left(i^{*}\left(p^{e}\right), p^{e}\right)<0\right)$.

Interpretation: Condition (1) can be given the following economic interpretation. The equilibrium share of domestic debt held at home increases following a marginal increase in the probability of

\footnotetext{
${ }^{24}$ Indeed, debt supply remains constant at $d_{1}$ while total demand decreases for a given $i$, as both domestic and foreign demand decrease. Thus, the market clearing condition imposes: $Q_{T}\left(i^{*}\left(p^{e}\right), p^{e}\right)=d_{1}=Q_{T}\left(i^{*}\left(p^{e^{2}}\right), p^{e^{2}}\right)$. As $\frac{\partial Q_{T}}{\partial i}(i)$ and $Q_{T}\left(i^{*}\left(p^{e}\right), p^{e}\right)>Q_{T}\left(i^{*}\left(p^{e}\right), p^{e^{2}}\right)$ due to increased risk and constant implicit return, if $i^{*}\left(p^{e}\right)>$ $i^{*}\left(p^{e^{2}}\right): d_{1}=Q_{T}\left(i^{*}\left(p^{e}\right), p^{e}\right)>Q_{T}\left(i^{*}\left(p^{e}\right), p^{e^{2}}\right)>Q_{T}\left(i^{*}\left(p^{e^{2}}\right), p^{e^{2}}\right)=d_{1}$, which is absurd. Therefore, $i^{*}\left(p^{e}\right)<$ $i^{*}\left(p^{e^{2}}\right)$. This is illustrated on Figure 7 below.
} 
default from $p^{e^{1}}$ to $p^{e^{2}}$ if and only if the increase in the equilibrium domestic implicit return is high enough relative to a quantity which decreases in the return on the risk-free asset and which increases in the implicit return on sovereign debt. Therefore, this condition is less restrictive when the exogenous risk-free return is higher, due to the fact that a similar riskless gain on savings can then be achieved by investing a lower share of post-consumption wealth in the risk-free asset. By contrast, this condition is more restrictive when the initial implicit domestic return on sovereign debt securities is higher. This relates to the fact that a similar expected gain can then be achieved on savings by taking less risk (that is, by investing a lower share of wealth in the risky asset).

If we denote by $z\left[i^{*}\left(p^{e}\right), p^{e}\right]$ the term which captures the variation in the expected implicit expected return following the increase in the expected probability of default, as market still clears for the same debt supply level $d_{1}$, Condition (1) mechanically implies that:

$$
z\left[i^{*}\left(p^{e}\right), p^{e}\right] \leq \frac{i_{F}\left[i^{*}\left(p^{e}\right), p^{e}\right]\left(i_{F}\left[i^{*}\left(p^{e}\right), p^{e}\right]-r_{f}+1\right)}{p^{e}\left(1+r_{f}\right)}
$$

which is less restrictive when the risk-free rate is lower and the initial implicit foreign return on sovereign debt securities is higher.

The necessary and sufficient Condition (1) is plausible as $s\left[i^{*}\left(p^{e}\right), p^{e}\right] \geq z\left[i^{*}\left(p^{e}\right), p^{e}\right]$ due to the negative risk impact on return for foreigners. Once again, this case arises if and only if, for a given $d_{1}, p\left(d_{1}, H^{2 *}, i^{*}\left(p^{e^{2}}\right)\right)=p^{e^{2}}>p^{e^{1}}$, such that the initially more pessimistic expectations are indeed validated in equilibrium. The mechanism behind such results is a self-fulfilling mechanism: if all creditors suddenly expect the probability of default to be higher for a given amount of government's indebtedness, this will indeed lead the probability of default to increase, as the higher $i^{*}\left(p^{e}\right)$ effectively raises the debt service. This mechanism arises due to the existence of strategic complementarities which make higher order beliefs matter: if an individual creditor believes the other creditors to believe that the probability of default is higher, it is optimal for him to act as he expects the other creditors to act, as these latter's aggregate decision impacts the government's decision.

Figure 7 provides a graphical example.

To sum-up, we identified a sufficient and necessary condition such that the model replicates the empirical result: more pessimistic expectations lead to higher market interest rate and home bias. 


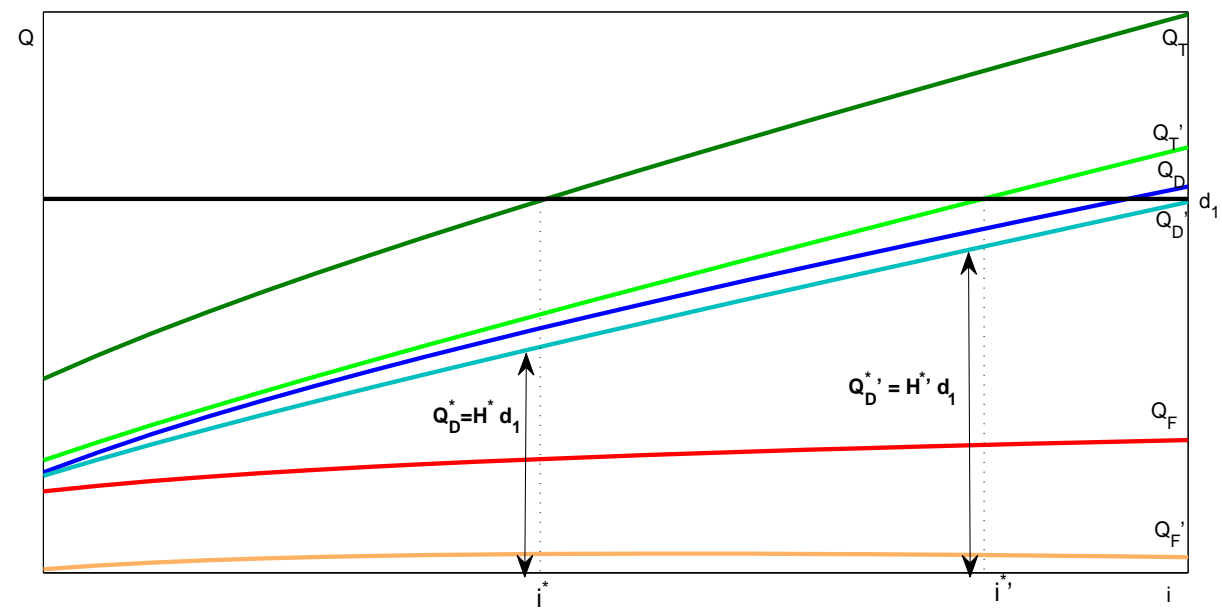

Figure 7: Endogenous home bias

Change in the government's decision We now assess the impact of the change in investors' optimal decision on the government's best response due to exogenously more pessimistic expectations triggering an increase in the market interest rate and in home bias in sovereign debt, in order to fully characterize the new subgame perfect Nash equilibrium.

Proposition 1: When the expected probability of default increases marginally, a switch from the government non-default equilibrium to the default equilibrium occurs if and only if:

$L_{f}\left(d_{1}, H^{*^{1}}, i^{*}\left(p^{e^{1}}\right), \tilde{x}\right)-L_{d}\left(d_{1}, H^{*^{1}}, i^{*}\left(p^{e^{1}}\right), \tilde{x}\right)<0$

and $\left.L_{f}\left(d_{1}, H^{*^{2}}, i^{*}\left(p^{e^{2}}\right)\right), \tilde{x}\right)-L_{d}\left(d_{1}, H^{*^{2}}, i^{*}\left(p^{e^{2}}\right), \tilde{x}\right)>0 \quad$ (2).

The distinct effects at work are the following. On the one hand, in the situation with more pessimistic expectations, the market interest rate $i^{*}\left(p^{e}\right)$ is higher, which makes the probability of default increase. This leads to a destabilizing effect of the change in expectations. On the other hand, the increase in home bias in equilibrium $H^{*}$ following the change in expectations causes a decrease in the incentives to default.

All in all, whether this leads to a switch in the government's decision depends on the value of $d_{1}$, on the shapes of the government's loss functions (which capture the relative effect of a destabilizing change in expectations and a stabilizing increase in home bias) and on the realization of the macroeconomic shock. The necessary and sufficient Condition (2) is satisfied if and only if the impact of the 
increase in the market interest rate $i^{*}\left(p^{e}\right)$ on the probability of default is strong enough relative to that of the increase in the equilibrium home bias $H^{*}$ and the realization of the worldwide shock $\tilde{x}$ is low enough.

\subsection{Change in equilibrium following exogenous changes in the expectations and in the fiscal fundamental}

We consider an initial equilibrium and we assess the consequences on the creditors and the government's decisions of an exogenous change in the fiscal fundamental, ${ }^{25}$ based on our prior empirical results, in order to show how these exogenous variations can cause home bias in sovereign debt to increase.

Shift in investors' decision We assess the impact of a marginal increase in the debt stock $d_{1}$ on the model's equilibrium. A marginal increase in $d_{1}$ raises the probability of default per se, as it increases the amount to be repaid. However, this also causes the market interest rate and the equilibrium home bias to vary (both through the effect of the new probability of default and of the new supply of debt which affects the market clearing equilibrium), which also impact in turn the probability of default. Therefore, starting from an initial equilibrium with expected probability of default $p^{e}\left(d_{1}\right)$, the expected probability of default endogenously switches to $p^{e}\left(d_{1}^{\prime}\right)$, capturing both the impact of the exogenous change in $d_{1}$ and of the endogenous change in $i^{*}\left(p^{e}\left(d_{1}\right)\right)$ and $H^{*}\left(d_{1}\right){ }^{26}$

The new equilibrium home bias $H^{*}\left(d_{1}^{\prime}\right)$ writes:

$$
H^{*}\left(d_{1}^{\prime}\right)=\frac{\left(\omega_{D}\left[i^{*}\left(p^{e}\left(d_{1}^{\prime}\right), d_{1}^{\prime}\right), p^{e}\left(d_{1}^{\prime}\right)\right]\right) W_{1}}{d_{1}^{\prime}(1+\beta)}
$$

Therefore, a necessary and sufficient condition for home bias to be higher in the new equilibrium is:

$v\left[i^{*}\left(p^{e}\left(d_{1}\right), d_{1}\right), p^{e}\left(d_{1}\right)\right] \geq \frac{i_{D}\left[i^{*}\left(p^{e}\left(d_{1}\right), d_{1}\right), p^{e}\left(d_{1}\right)\right]\left(i_{D}\left[i^{*}\left(p^{e}\left(d_{1}\right), d_{1}\right), p^{e}\left(d_{1}\right)\right]-r_{f}+1\right)}{p^{*}\left(1+r_{f}\right)} \frac{d_{1}^{\prime}}{d_{1}}$,

with $\frac{d_{1}^{\prime}}{d_{1}} \rightarrow 1$. The quantity $v\left[i^{*}\left(p^{e}\left(d_{1}\right), d_{1}\right), p^{e}\left(d_{1}\right)\right]$ captures the impact of a marginal increase in $d_{1}$ on

\footnotetext{
${ }^{25}$ We focus on the impact of a change in the fiscal fundamental, that is in the debt. However, the reasoning would be perfectly similar for an exogenous change in the growth rate, which could also be introduced as a variable in the probability of default function. The necessary and sufficient condition such that an increase in home bias associated with an increase in the interest rate is replicated following an exogenous change in the growth rate would be exactly the same as that following an exogenous change in the fiscal fundamental, except that the debt would be set constant.

${ }^{26}$ Contrary to the previous case in which debt $d_{1}$ was set constant, we now make clear which variables depend on $d_{1}$.
} 
the implicit domestic return on sovereign debt securities. It is equal to:

$$
\begin{array}{r}
\frac{\partial i_{D}}{\partial i}\left[i^{*}\left(p^{e}\left(d_{1}\right), d_{1}\right), p^{e}\left(d_{1}\right)\right]\left(\frac{\partial i^{*}}{\partial p^{e}}\left[i^{*}\left(p^{e}\left(d_{1}\right), d_{1}\right), p^{e}\left(d_{1}\right)\right]\left(p^{e}\right)^{\prime}\left(d_{1}\right)+\frac{\partial i^{*}}{\partial d_{1}}\left[i^{*}\left(p^{e}\left(d_{1}\right), d_{1}\right), p^{e}\left(d_{1}\right)\right]\right) \\
+\frac{\partial i_{D}}{\partial p^{e}}\left[i^{*}\left(p^{e}\left(d_{1}\right), d_{1}\right), p^{e}\left(d_{1}\right)\right]\left(p^{e}\right)^{\prime}\left(d_{1}\right) .
\end{array}
$$

This term captures first the impact of a higher debt stock $d_{1}$ on the implicit return through its overall impact on the market interest rate:

$$
\frac{\partial i_{D}}{\partial i}\left[i^{*}\left(p^{e}\left(d_{1}\right), d_{1}\right), p^{e}\left(d_{1}\right)\right]\left(\frac{\partial i^{*}}{\partial p^{e}}\left[i^{*}\left(p^{e}\left(d_{1}\right), d_{1}\right), p^{e}\left(d_{1}\right)\right]\left(p^{e}\right)^{\prime}\left(d_{1}\right)+\frac{\partial i^{*}}{\partial d_{1}}\left[i^{*}\left(p^{e}\left(d_{1}\right), d_{1}\right), p^{e}\left(d_{1}\right)\right]\right) .
$$

It depends on the impact of a higher interest rate on the implicit domestic return $\frac{\partial i_{D}}{\partial i}\left[i^{*}\left(p^{e}\left(d_{1}\right), d_{1}\right), p^{e}\left(d_{1}\right)\right]>0$, on the impact of a higher expected probability of default on the market interest rate $\frac{\partial i^{*}}{\partial p^{e}}\left[i^{*}\left(p^{e}\left(d_{1}\right), d_{1}\right), p^{e}\left(d_{1}\right)\right]>0$, on the impact of a higher debt level on the expected probability of default $\left(p^{e}\right)^{\prime}\left(d_{1}\right)$ which sign is ambiguous, and on the impact of a higher debt level on the market interest rate $\left.\frac{\partial i^{*}}{\partial d_{1}}\left[i^{*}\left(p^{e}\left(d_{1}\right), d_{1}\right), p^{e}\left(d_{1}\right)\right]\right)>0$.

Second, it captures the impact of a marginal increase in debt on the implicit domestic return through its impact on the expected probability of default $\frac{\partial i_{D}}{\partial p^{e}}\left[i^{*}\left(p^{e}\left(d_{1}\right), d_{1}\right), p^{e}\left(d_{1}\right)\right]\left(p^{e}\right)^{\prime}\left(d_{1}\right)$, with $\frac{\partial i_{D}}{\partial p^{e}}\left[i^{*}\left(p^{e}\left(d_{1}\right), d_{1}\right), p^{e}\left(d_{1}\right)\right]>0$.

Once again, Condition (3) is less restrictive when the risk-free rate $r_{f}$ is higher and when the initial domestic implicit return on sovereign debt is lower. Obviously, a sufficient condition for $i^{*}\left(p^{e}\left(d_{1}\right), d_{1}\right)$ to increase as well following a marginal increase in the debt is that total demand decreases for a given $i$ (which is satisfied as soon as $\left.p^{e}\left(d_{1}\right)<p^{e}\left(d_{1}^{\prime}\right)\right) .{ }^{27}$ Figure 8 provides a graphical example. ${ }^{28}$ Therefore, the debt crisis model enables to identify conditions under which a marginal change in debt triggers a simultaneous increase in home bias in sovereign debt and in the nominal return on sovereign debt. We now assess the impact of this shift on the government's decision of default. We show that this impact depends on the initial causes of the increase in home bias, which reveals that it matters to identify them for assessing the consequences for sovereign debt crisis, in particular in the case of domestic shocks.

\footnotetext{
${ }^{27}$ Indeed, in this case, we have $\frac{\partial Q_{T}}{\partial i}\left[i, p^{e}\left(d_{1}\right)\right]>0$ and $Q_{T}\left[i^{*}\left(p^{e}\left(d_{1}\right), d_{1}\right), p^{e}\left(d_{1}\right)\right]>Q_{T}\left[i^{*}\left(p^{e}\left(d_{1}\right), d_{1}\right), p^{e}\left(d_{1}^{\prime}\right)\right]$ Therefore, if $i^{*}\left(p^{e}\left(d_{1}\right), d_{1}\right)>i^{*}\left(p^{e}\left(d_{1}^{\prime}\right), d_{1}^{\prime}\right): d_{1}=Q_{T}\left[i^{*}\left(p^{e}\left(d_{1}\right), d_{1}\right), p^{e}\left(d_{1}\right)\right]>Q_{T}\left[i^{*}\left(p^{e}\left(d_{1}\right), d_{1}\right), p^{e}\left(d_{1}^{\prime}\right)\right]>$ $Q_{T}\left[i^{*}\left(p^{e}\left(d_{1}^{\prime}\right), d_{1}^{\prime}\right), p^{e}\left(d_{1}^{\prime}\right)\right]=d_{1}^{\prime}$, which is absurd.

${ }^{28}$ In order to make the chart clearer, we figure an increase in $d_{1}$ which is not a marginal increase strictly speaking.
} 


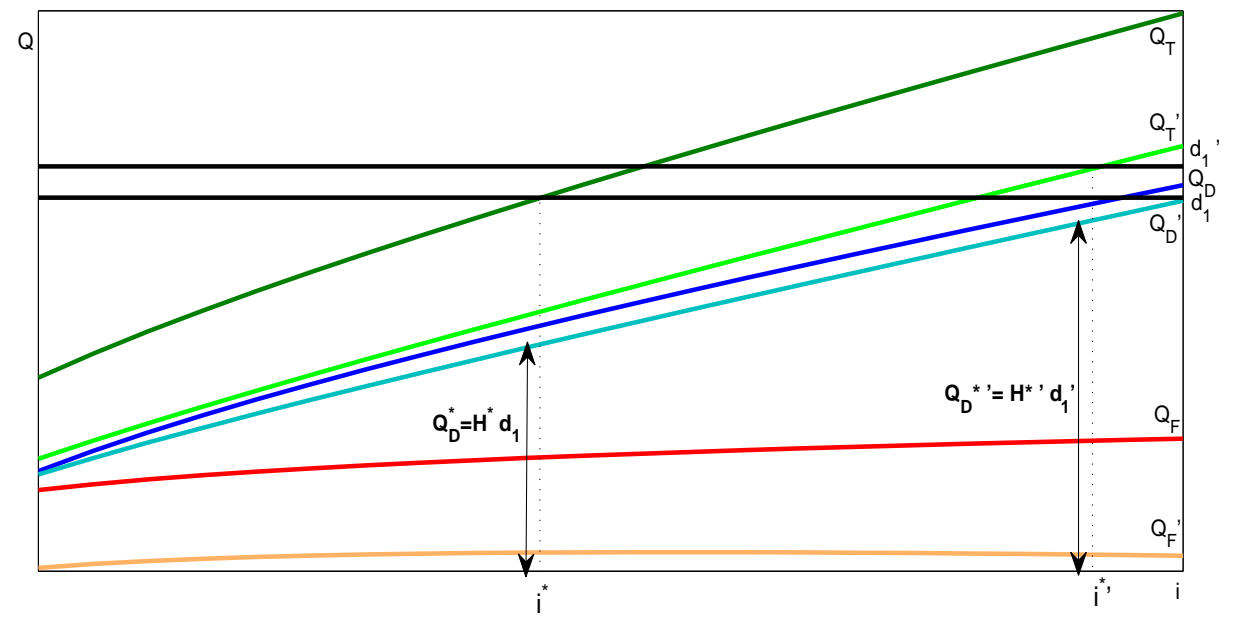

Figure 8: Higher fiscal fundamental

Change in the government's decision We assess the impact of the change in investors' optimal decision on the government's best response due to exogenously worst fiscal fundamental triggering an increase in the market interest rate and in home bias in sovereign debt, in order to fully characterize the new subgame perfect Nash equilibrium.

Proposition 2: When the fiscal fundamental increases marginally, a switch from the non-default equilibrium to the default equilibrium occurs if and only if:

$L_{f}\left(d_{1}, H^{*}\left(d_{1}\right), i^{*}\left(p^{e}\left(d_{1}\right), d_{1}\right), \tilde{x}\right)-L_{d}\left(d_{1}, H^{*}\left(d_{1}, i^{*}\left(p^{e}\left(d_{1}\right), d_{1}\right), \tilde{x}\right)<0\right.$

and $L_{f}\left(d_{1}^{\prime}, H^{*}\left(d_{1}^{\prime}\right), i^{*}\left(p^{e}\left(d_{1}^{\prime}\right), d_{1}^{\prime}\right), \tilde{x}\right)-L_{d}\left(d_{1}^{\prime}, H^{*}\left(d_{1}^{\prime}\right), i^{*}\left(p^{e}\left(d_{1}^{\prime}\right), d_{1}^{\prime}\right), \tilde{x}\right)>0$

On the one hand, the increase in the fiscal fundamental raises the probability of default. It also causes the market interest rate to increase, which further raises the probability of default. On the other hand, the increase in home bias that it triggers partly contains this rise. Condition (4) provides a necessary and sufficient condition such that a switch in the government's best response occurs in the case of the fiscal fundamental shock. It is satisfied when the size of the positive impact of the marginal increase in debt and of the endogenous increase in the market interest rate on the probability of default is high enough relative to that (negative) of the endogenous increase in home bias and if the realization of the macroeconomic shock $\tilde{x}$ is low enough.

Therefore, an increase in home bias reflects the existence of an exogenous source of fragility that can 
lead to a switch in the government's decision, but this is not an ex post additional source of fragility itself. On the reverse, it plays a stabilizing role - notably through political costs - that mitigates the effect of the ex ante source of fragility that triggered it, and makes the condition for a switch in the government's decision towards default less likely. We have identified and interpreted a sufficient condition, both in the case of a change in expectations and a change in the fiscal fundamental, such that the situation that triggers an increase in home bias ends up in sovereign default. Nevertheless, if this condition is not satisfied, defaulting remains suboptimal for the government, either because home bias increases enough to partly counterbalance the deteriorating macroeconomic conditions or because the deterioration in those conditions is not sufficient to alleviate the government's cost of default.

\section{Conclusion}

Empirical investigation reveals that, as expected, domestic shocks related to countries' fiscal sustainability significantly affect the dynamics of home bias in sovereign debt holdings in the Euro area. The impact of fundamental shocks appears to be the most robust one, as it holds both in all panel tests and all country-specific tests. However, country-specific expectations shocks prove to have a significant impact on home bias in several GIIPS countries, those which were actually identified as prone to selffulfilling market sentiment. In addition, we relativize the view held in the theoretical literature that an increase in home bias is destabilizing per se through its impact on the growth rate. These results are robust to alternative identification strategies.

A simple model of sovereign debt crisis shedding light on the cost of default and providing microfoundations for investors' decision allows us to provide a theoretical explanation to the transmission of exogenous changes in domestic variables to the share of debt held by domestic creditors in accordance with the literature, and to investigate the potential overall consequences of an increase in this share when it is driven by a sudden worsening in the sovereign debt situation. We show that whether a sovereign default becomes optimal for the government following this worsening depends on the relative effects of the increase in home bias and of the source of fragility that triggered it.

If the increase in home bias is sufficiently high compared to the worsening in fundamentals and in expectations, it may act as a counteracting mechanism, which can ultimately prevent default. However, if such increase can ease fiscal stress in the short term, it does not in itself preclude the need for policy measures aimed at containing the worsening in fiscal conditions in the longer run. The de- 
crease in home bias in sovereign debt that was observed in most Euro area countries in the first half of 2015 suggests that ECB injection liquidity measures have proven successful in restoring confidence, inducing foreign investors to return to Eurozone sovereign debt markets.

\section{References}

Acharya, V., Drechsler, I., and Schnabl, P. (2012). A Tale of Two Overhangs: the Nexus of Financial Sector and Sovereign Credit Risks. Financial Stability Review, 16: 51-56.

Acharya, V. V., Drechsler, I., and Schnabl, P. (2014). A Pyrrhic Victory? Bank Bailouts and Sovereign Credit Risk. Journal of Finance, 69(6): 2689-2739.

Aguiar, M., Amador, M., Farhi, E., and Gopinath, G. (2014). Coordination and Crisis in Monetary Unions. NBER Working Paper, 20277.

Allegret, J., Beker Puca, E., Gimet, C., and Josifidis, K. (2014). Macroeconomic Policy Responses to Financial Crises in European Emerging Economies. Economic Modelling, 36: 577-591.

Andritzky, J. (2012). Government Bonds and Their Investors: What Are the Facts and Do They Matter? IMF Working Paper, 158.

Battistini, N., Pagano, M., and Simonelli, S. (2014). Systemic Risk and Home Bias in the Euro Area. Economic Policy, 29: 203-251.

Beetsma, R., Giulodori, M., and Klaasen, F. (2006). Trade Spill-overs of Fiscal Policy in the European Union: a Panel Analysis. Economic Policy, 21(48): 639-687.

Blot, C., Ducoudré, B., and Timbeau, X. (2015). Sovereign Debt Spread and Default in a Simple Model with Self-fulfilling Prophecies and Asymmetric Information. OFCE Working Paper, 12.

Broner, F., Erce, A., Martin, A., and Ventura, J. (2014). Sovereign Debt Markets in Turbulent Times: Creditor Discrimination and Crowding-out Effects. Journal of Monetary Economics, 61: 114-142.

Bruneau, C., Delatte, A., and Fouquau, J. (2014). Is the European Sovereign Crisis Self-fulfilling? Empirical Evidence about the Drivers of Market Sentiments. Journal of Macroeconomics, 42: 38-51.

Brutti, F. and Sauré, P. (2015). Repatriation of Debt in the Euro Crisis: Evidence for the Secondary Market Theory. Journal of the European Economic Association, forthcoming. 
Calvo, G. (1988). Servicing the Public Debt: the Role of Expectations. American Economic Review, 78(4): 647-661.

Canova, F. and Ciccarelli, M. (2013). Panel Vector Autoregressive Models: a Survey, volume 32: 205-246. Emerald Group Publishing Limited.

Cantero-Saiz, M., Sanfilippo-Azofra, S., Torre-Olmo, B., and Lopez-Gutierrez, C. (2014). Sovereign Risk and the Bank Lending Channel in Europe. Journal of International Money and Finance, 47: 1-20.

Cole, H. and Kehoe, T. (2000). Self-fulfilling Debt Crises. Review of Economic Studies, 67: 91-116.

Corsetti, G. and Dedola, L. (2011). Fiscal Crises, Confidence and Default. A Bare-bones Model with Lessons for the Euro Area. Mimeo.

Corsetti, G. and Dedola, L. (2013). The Mystery of the Printing Press: Self-fulfilling Debt Crises and Monetary Sovereignty. CEPR Discussion Paper, 9358.

De Grauwe, P. and Ji, Y. (2013). Self-fulfilling Crises in the Eurozone: an Empirical Test. Journal of International Money and Finance, 34:15-36.

Favero, C. and Giavazzi, F. (2008). Should the Euro Area be Run as a Closed Economy? American Economic Review, 98(2): 138-145.

Gennaioli, N., Martin, A., and Rossi, S. (2014). Sovereign Default, Domestic Banks and Financial Institutions. Journal of Finance, 69(2): 819-866.

Gonzalez-Hermosillo, B. and Johnson, C. (2014). Transmission of Financial Stress in Europe: The Pivotal Role of Italy and Spain, but not Greece. IMF Working Paper Series, 76.

Gros, D. (2012). A Simple Model of Multiple Equilibria and Default. CEPS Working document, 366.

Kilian, L. and Chang, P. (2000). How accurate are Confidence Intervals for Impulse Responses in Large VAR Models? Economics Letters, 69: 299-307.

Kim, S. (2005). Monetary policy, Foreign Exchange Policy, and Delayed Overshooting. Journal of Money, Credit and Banking, 37(4):775-782.

Kim, S. and Roubini, N. (2000). Exchange Rate Anomalies in the Industrialized Countries: a Solution with a Structural var Approach. Journal of Monetary Economics, 45: 561-586. 
Lorenzoni, G. and Werning, I. (2013). Slow Moving Debt Crises. NBER Working Paper, 19228.

MacDonald, R., Sogiakas, V., and Tsopanakis, A. (2015). An Investigation of Systemic Stress and Interdependencies within the Eurozone and Euro Area Countries. Economic Modelling, 48: 52-69.

Mackowiack, B. (2007). External Shocks, US Monetary Policy and Macroeconomic Fluctuations in Emerging Markets. Journal of Monetary Economics, 54(8):2512-2520.

Matsumoto, A. (2015). Global Liquidity: Availability of Funds for Safe and Risky assets. IMF Working Papers, 11/136.

Mengus, E. (2014). Honoring Sovereign Debt or Bailing Out Domestic Residents? A Theory of Internal Costs of Default. Working Paper Banque de France, 480.

Merler, S. and Pisani-Ferry, J. (2012). Who's Afraid of Sovereign Bonds? Bruegel Policy Contribution, 02.

Obstfeld, M. (1996). Models of Currency Crises with Self-fulfilling Features. European Economic Review, 40(3-5): 1037-1047.

Panizza, U., Sturzenegger, F., and Zettelmeyer, J. (2009). The Economics and Law of Sovereign Default. Journal of Economic Literature, 47(3): 651-698.

Prieto, E., Eickmeier, S., and Marcellino, M. (2013). Time Variation in Macro-Financial Linkages. CEPR Discussion Papers, 9436.

Raileanu-Szeles, M. and Albu, L. (2015). Non-linearities and Divergences in the Process of European Financial Integration. Economic Modelling, 46: 416-425.

Reinhart, C. and Sbrancia, S. (2015). The Liquidation of Government Debt. Economic Policy, forthcoming.

Schmidt, T. and Zwick, L. (2015). Uncertainty and Episodes of Extreme Capital Flows in the Euro Area. Economic Modelling, 48: 343-356.

Schumacher, I. (2014). On the Self-fulfilling Prophecy of Changes in Sovereign Ratings. Economic Modelling, 38: 351-356.

Sims, C. (1988). Bayesian Skepticism on Unit root Econometrics. Journal of Economic Dynamics and Control, 12(2-3): 463-474. 
Sims, C. and Uhlig, H. (1991). Understanding Unit Rooters: a Helicopter Tour. Econometrica, 59(6): 1591-99.

Sims, C. and Zha, T. (1998). Bayesian Methods for Dynamic Multivariate Models. International Economic Review, 39(4): 949-968.

Sims, C. and Zha, T. (1999). Error Bands for Impulse Responses. Econometrica, 67(5): 1113-1156.

Uhlig, H. (1994). What Macroeconomists Should Know About Unit Roots. Econometric Theory, 10(3-4): 645-671.

Van Riet, A. (2014). Managing High Public Debt in Euro Area Countries: Financial Repression as a Fiscal Insurance? ECB Draft Document. 


\section{A Data on home bias in sovereign debt}

\begin{tabular}{|c|c|c|c|}
\hline Country & Data & Valuation & Source \\
\hline France & Debt Securities & Market Value & Bank of France \\
\hline Germany & Debt Liabilities & Nominal Value & Deutsche Bundesbank \\
\hline Greece & Debt Securities & Market Value & Bank of Greece \\
\hline Ireland & Long-Term Bonds & Nominal Value & Central Bank of Ireland \\
\hline Italy & Debt Securities & Nominal Value & Bank of Italy \\
\hline Portugal & Debt Securities & Nominal Value & Bank of Portugal \\
\hline Spain & Debt Securities & Market Value & Bank of Spain \\
\hline
\end{tabular}

\section{B Impulse response functions}
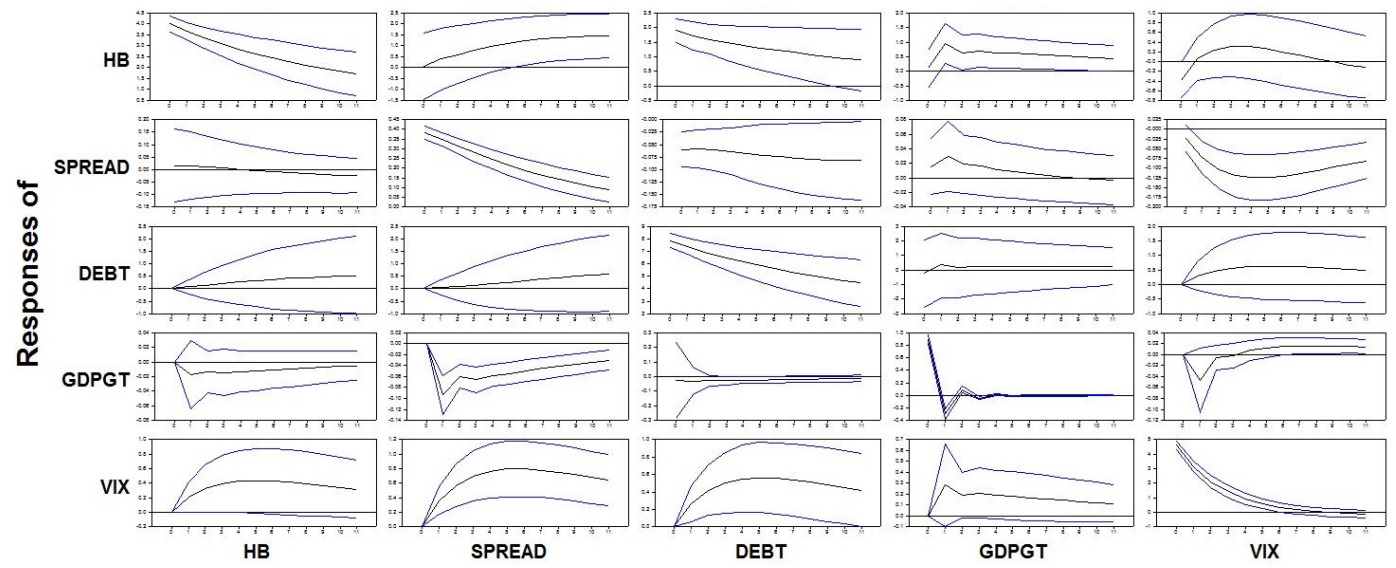

Figure 9: Impulse response functions - Whole sample over the period 2002-2007 

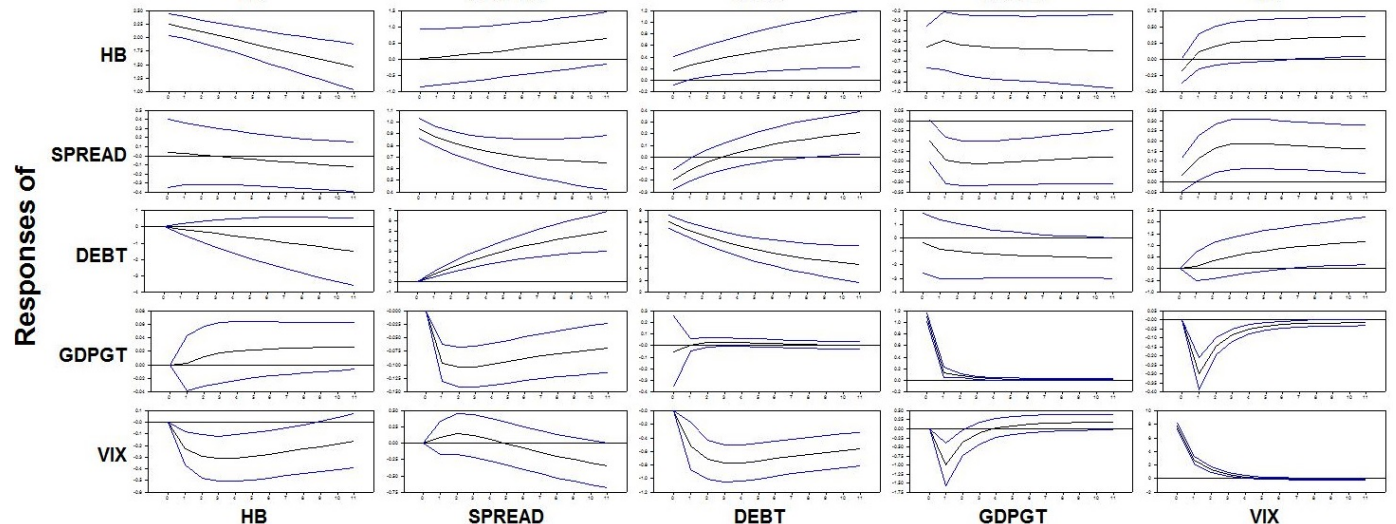

Figure 10: Impulse response functions - Whole sample over the period 2008-2014
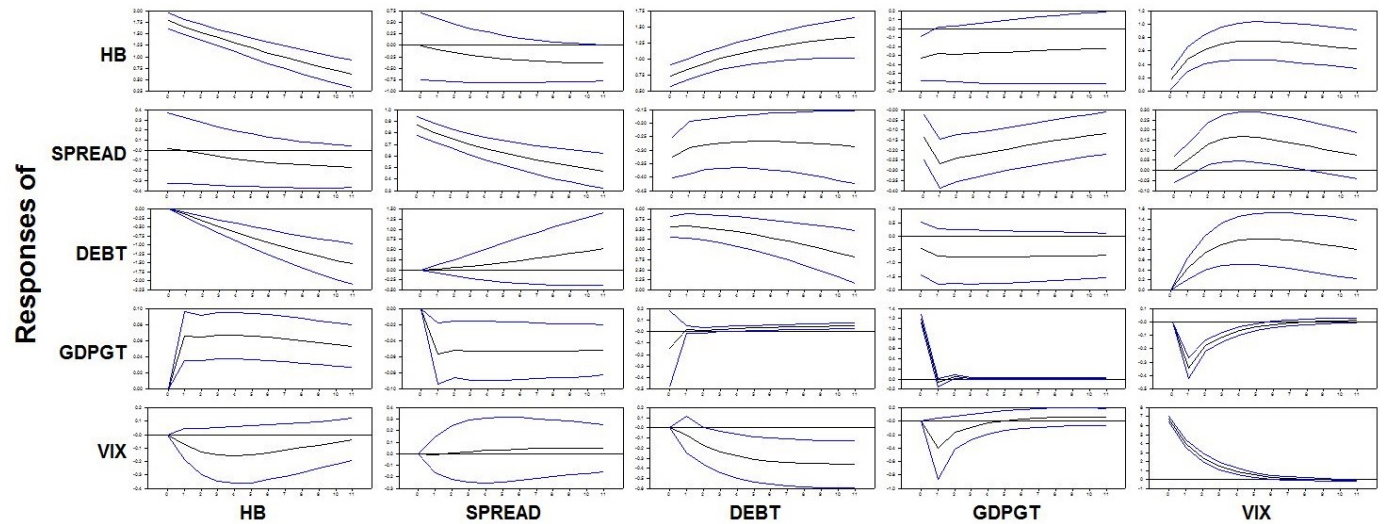

Figure 11: Impulse response functions - Panel of 4 countries (Greece, Ireland, Italy, Spain)

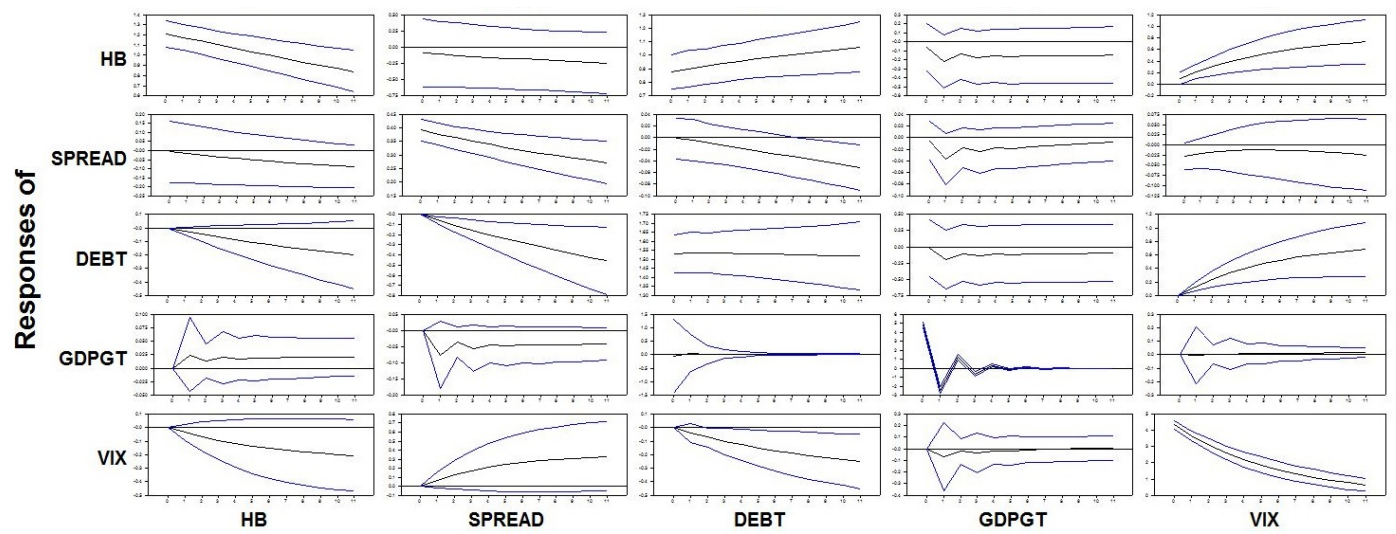

Figure 12: Impulse response functions - Ireland 


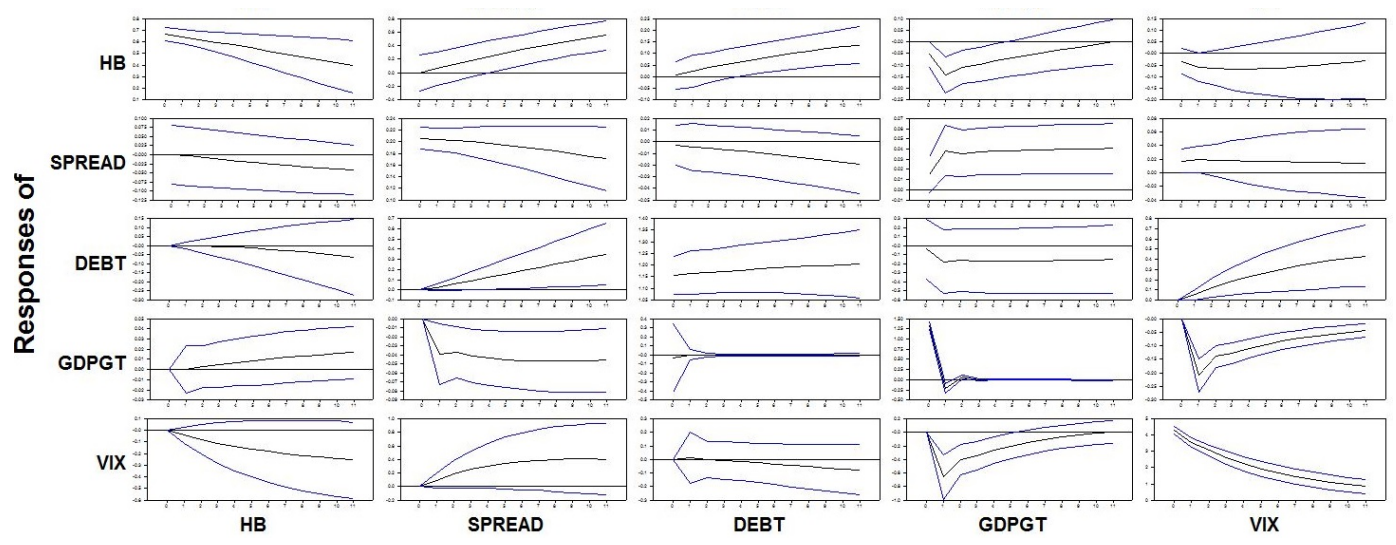

Figure 13: Impulse response functions - Italy

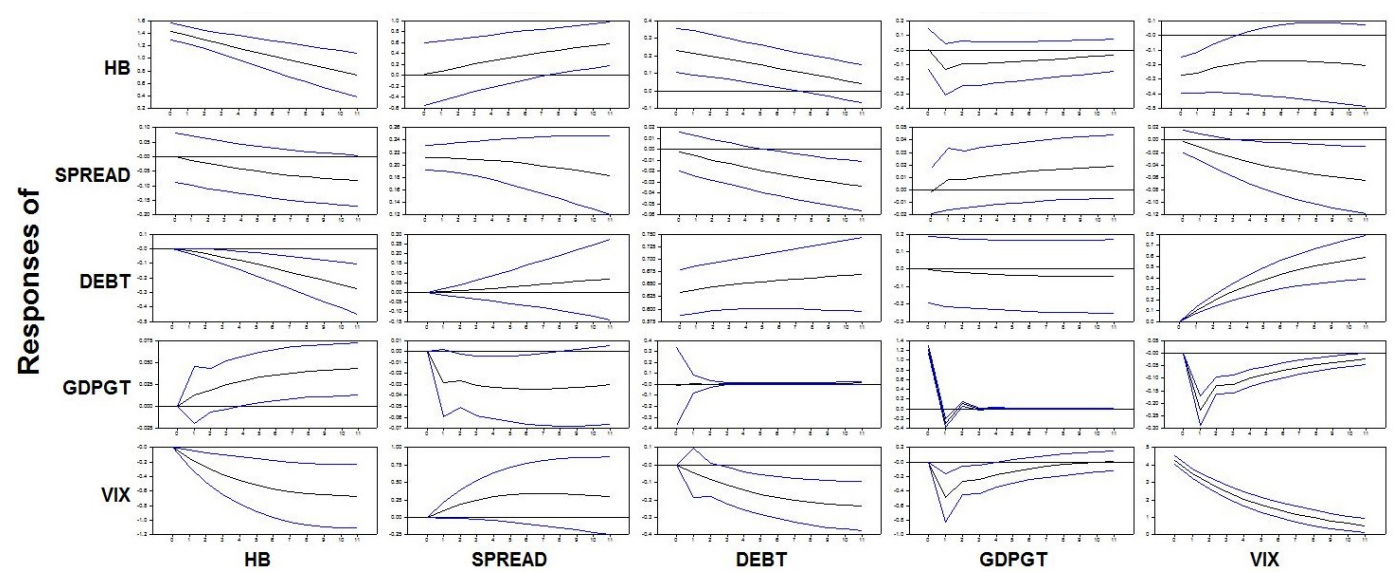

Figure 14: Impulse response functions - Spain
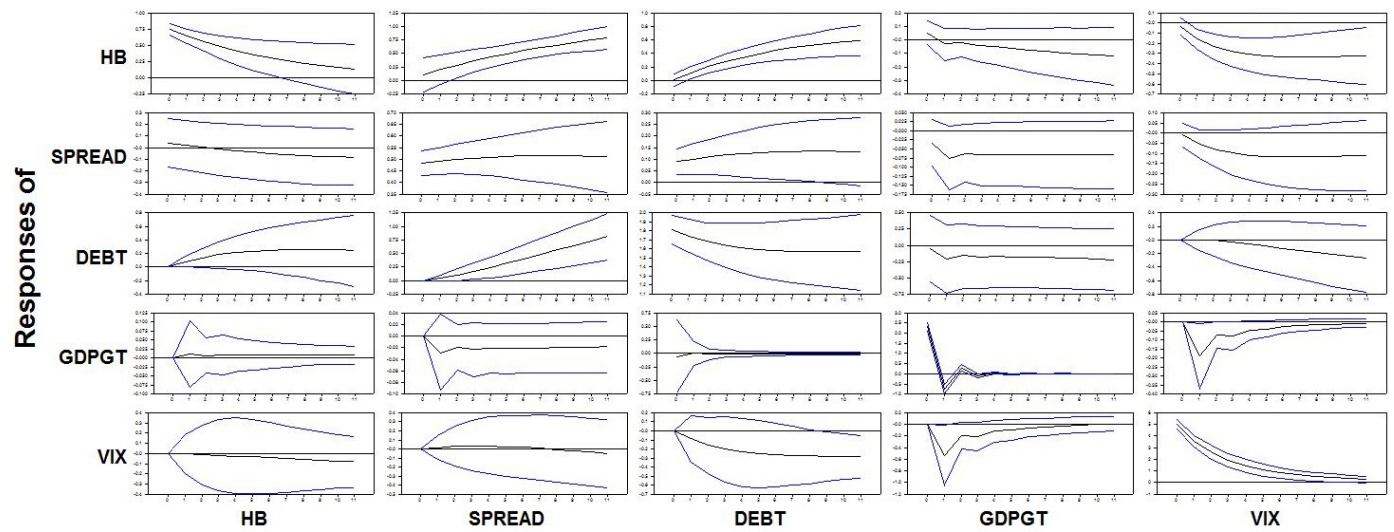

Figure 15: Impulse response functions - Portugal 

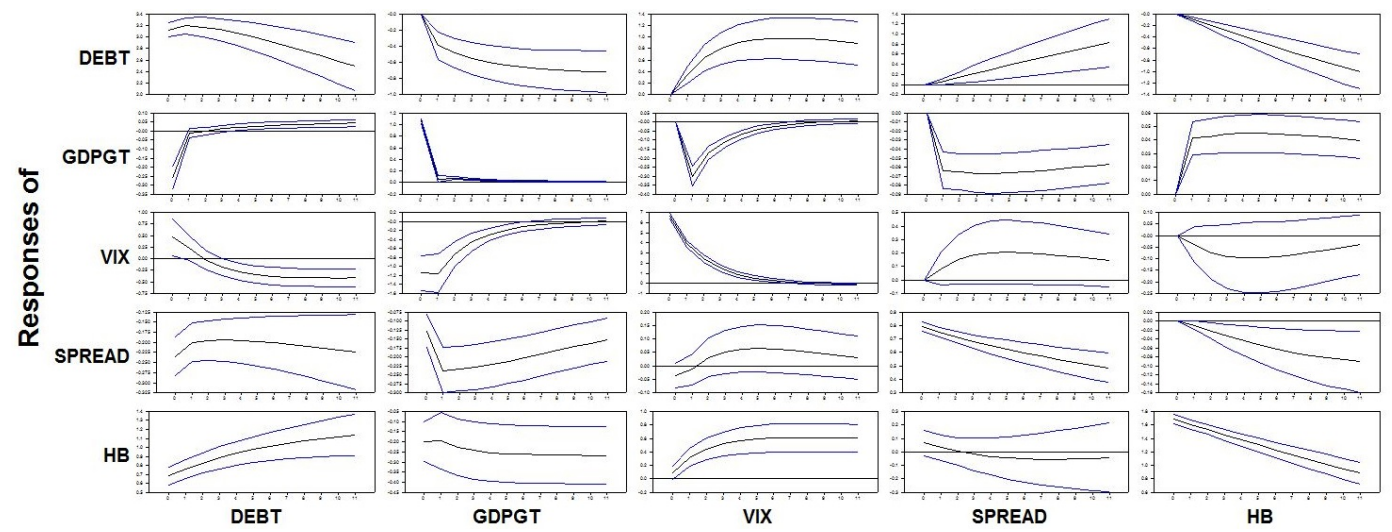

Figure 16: Impulse response functions - First Cholesky decomposition
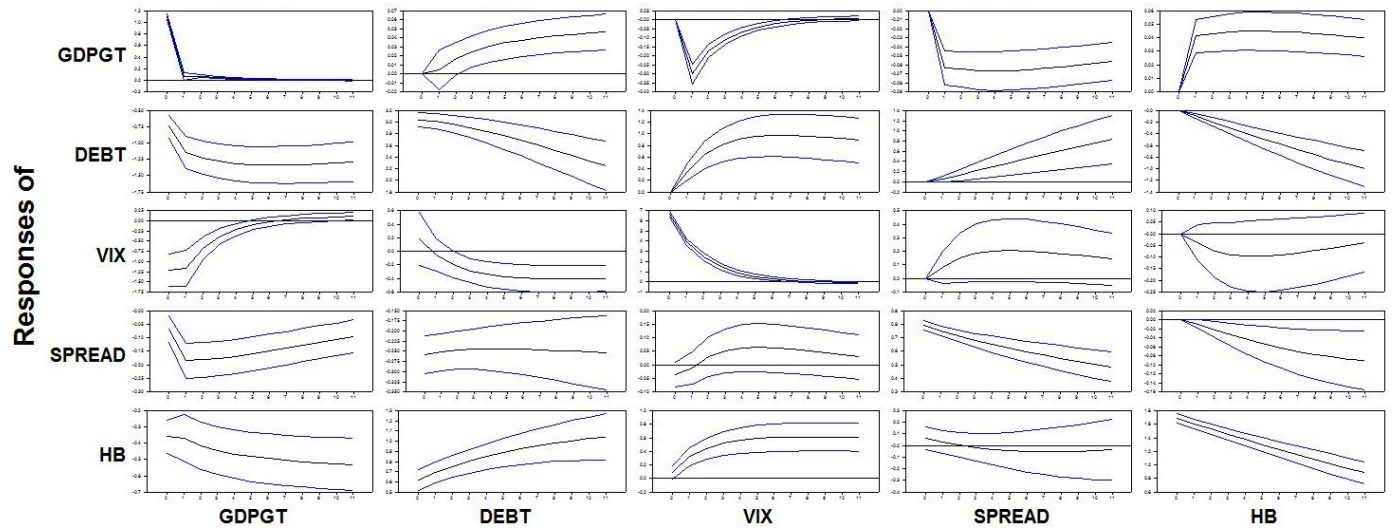

Figure 17: Impulse response functions - Second Cholesky decomposition
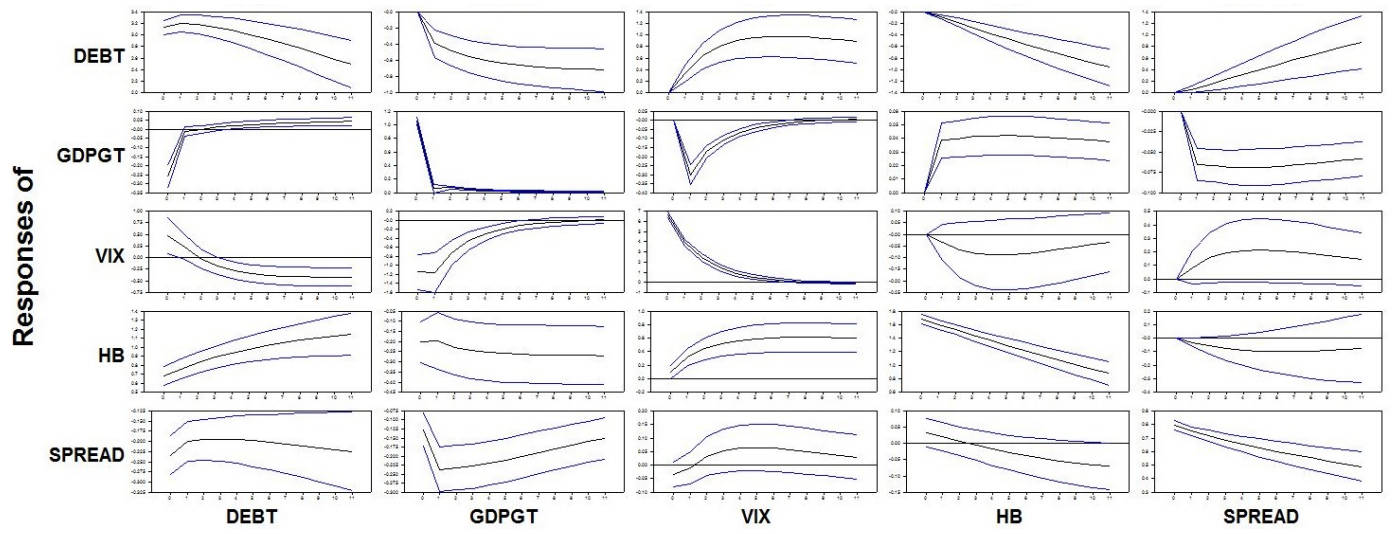

Figure 18: Impulse response functions - Third Cholesky decomposition 


\section{Forecast Error Variance Decompositions}

\begin{tabular}{|c|c|c|c|c|c|c|c|c|c|}
\hline Vix shock (\%) & $\mathrm{hb}$ & spread & debt & gdp & Spread shock (\%) & $\mathrm{hb}$ & debt & gdp & vix \\
\hline 1 & 0.35 & 0.28 & 0.00 & 0.00 & 1 & 3.58 & 0.00 & 0.00 & 0.00 \\
\hline 2 & 1.82 & 0.35 & 0.62 & 7.06 & 2 & 3.46 & 0.02 & 0.30 & 0.02 \\
\hline 3 & 3.32 & 0.50 & 1.77 & 9.13 & 3 & 3.36 & 0.07 & 0.60 & 0.06 \\
\hline 4 & 4.65 & 0.63 & 2.93 & 9.87 & 4 & 3.24 & 0.17 & 0.91 & 0.11 \\
\hline 8 & 8.22 & 0.92 & 5.86 & 10.09 & 8 & 3.11 & 1.01 & 2.08 & 0.36 \\
\hline 12 & 10.06 & 0.99 & 6.91 & 9.92 & 12 & 3.09 & 2.53 & 2.97 & 0.54 \\
\hline Debt shock (\%) & $\mathrm{hb}$ & spread & gdp & vix & Hb shock (\%) & spread & debt & gdp & vix \\
\hline 1 & 11.64 & 8.06 & 4.49 & 0.00 & 1 & 3.76 & 0.00 & 0.00 & 0.00 \\
\hline 2 & 13.00 & 7.83 & 4.16 & 0.04 & 2 & 3.67 & 0.04 & 0.12 & 0.01 \\
\hline 3 & 14.37 & 7.88 & 4.10 & 0.12 & 3 & 3.64 & 0.13 & 0.25 & 0.02 \\
\hline 4 & 15.73 & 8.04 & 4.10 & 0.25 & 4 & 3.60 & 0.29 & 0.38 & 0.04 \\
\hline 8 & 21.05 & 9.04 & 4.45 & 1.01 & 8 & 3.76 & 1.45 & 0.89 & 0.13 \\
\hline 12 & 26.18 & 10.38 & 5.02 & 1.84 & 12 & 4.08 & 3.38 & 1.33 & 0.20 \\
\hline Gdp shock (\%) & $\mathrm{hb}$ & spread & debt & vix & & & & & \\
\hline 1 & 2.15 & 1.53 & 4.50 & 0.00 & & & & & \\
\hline 2 & 2.01 & 3.98 & 5.55 & 0.35 & & & & & \\
\hline 3 & 2.05 & 4.69 & 5.97 & 0.43 & & & & & \\
\hline 4 & 2.12 & 5.05 & 6.24 & 0.46 & & & & & \\
\hline 8 & 2.46 & 5.39 & 6.89 & 0.58 & & & & & \\
\hline 12 & 2.89 & 5.26 & 7.22 & 0.70 & & & & & \\
\hline
\end{tabular}

Table 1: Variance decomposition - Whole sample

\begin{tabular}{|c|c|c|c|c|c|c|c|c|c|}
\hline Vix shock (\%) & $\mathrm{hb}$ & spread & debt & gdp & Spread shock (\%) & $\mathrm{hb}$ & debt & gdp & vix \\
\hline 1 & 0.78 & 0.58 & 0.00 & 0.00 & 1 & 3.18 & 0.00 & 0.00 & 0.00 \\
\hline 2 & 0.88 & 1.91 & 0.13 & 0.28 & 2 & 3.48 & 0.03 & 0.92 & 0.44 \\
\hline 3 & 1.11 & 3.72 & 0.32 & 0.31 & 3 & 4.00 & 0.10 & 1.28 & 1.33 \\
\hline 4 & 1.29 & 5.40 & 0.53 & 0.35 & 4 & 4.65 & 0.19 & 1.71 & 2.51 \\
\hline 8 & 1.69 & 9.96 & 1.17 & 0.56 & 8 & 8.09 & 0.74 & 2.75 & 7.51 \\
\hline 12 & 2.00 & 11.45 & 1.54 & 0.72 & 12 & 11.85 & 1.39 & 3.23 & 10.59 \\
\hline Debt shock (\%) & $\mathrm{hb}$ & spread & gdp & vix & Hb shock (\%) & spread & debt & gdp & vix \\
\hline 1 & 15.94 & 2.02 & 4.13 & 0.00 & 1 & 3.83 & 0.00 & 0.00 & 0.00 \\
\hline 2 & 15.55 & 2.18 & 4.27 & 0.23 & 2 & 3.81 & 0.03 & 0.10 & 0.16 \\
\hline 3 & 15.45 & 2.43 & 4.42 & 0.69 & 3 & 3.82 & 0.10 & 0.15 & 0.47 \\
\hline 4 & 15.26 & 2.72 & 4.54 & 1.27 & 4 & 3.81 & 0.20 & 0.20 & 0.87 \\
\hline 8 & 14.43 & 4.56 & 4.96 & 3.59 & 8 & 4.29 & 0.76 & 0.34 & 2.43 \\
\hline 12 & 13.82 & 6.71 & 5.33 & 4.86 & 12 & 5.16 & 1.43 & 0.45 & 3.31 \\
\hline Gdp shock (\%) & $\mathrm{hb}$ & spread & debt & vix & & & & & \\
\hline 1 & 1.03 & 0.55 & 4.01 & 0.00 & & & & & \\
\hline 2 & 3.00 & 0.93 & 4.39 & 0.35 & & & & & \\
\hline 3 & 2.96 & 0.89 & 4.33 & 0.44 & & & & & \\
\hline 4 & 3.08 & 0.90 & 4.32 & 0.57 & & & & & \\
\hline 8 & 3.14 & 1.01 & 4.21 & 0.94 & & & & & \\
\hline 12 & 3.13 & 1.19 & 4.06 & 1.11 & & & & & \\
\hline
\end{tabular}

Table 2: Variance decomposition - Whole sample 2002-2007 


\begin{tabular}{|c|c|c|c|c|c|c|c|c|c|}
\hline Vix shock (\%) & $\mathrm{hb}$ & spread & debt & gdp & Spread shock (\%) & $\mathrm{hb}$ & debt & gdp & vix \\
\hline 1 & 0.65 & 0.42 & 0.00 & 0.00 & 1 & 3.87 & 0.00 & 0.00 & 0.00 \\
\hline 2 & 1.03 & 1.11 & 0.15 & 6.30 & 2 & 3.86 & 0.45 & 0.70 & 0.05 \\
\hline 3 & 1.21 & 1.74 & 0.29 & 7.71 & 3 & 3.88 & 1.48 & 1.46 & 0.13 \\
\hline 4 & 1.33 & 2.26 & 0.43 & 8.05 & 4 & 4.00 & 2.98 & 2.18 & 0.21 \\
\hline 8 & 1.69 & 3.30 & 0.98 & 8.11 & 8 & 4.95 & 11.72 & 4.27 & 0.55 \\
\hline 12 & 1.99 & 3.52 & 1.44 & 8.01 & 12 & 6.79 & 20.88 & 5.51 & 1.26 \\
\hline Debt shock (\%) & $\mathrm{hb}$ & spread & gdp & vix & Hb shock $(\%)$ & spread & debt & gdp & vix \\
\hline 1 & 0.78 & 3.47 & 4.09 & 0.00 & 1 & 4.00 & 0.00 & 0.00 & 0.00 \\
\hline 2 & 1.05 & 2.48 & 3.87 & 0.43 & 2 & 3.94 & 0.04 & 0.04 & 0.08 \\
\hline 3 & 1.40 & 2.01 & 3.89 & 1.16 & 3 & 3.90 & 0.12 & 0.10 & 0.21 \\
\hline 4 & 1.75 & 1.94 & 3.98 & 1.97 & 4 & 3.88 & 0.25 & 0.16 & 0.36 \\
\hline 8 & 3.45 & 2.59 & 4.35 & 4.69 & 8 & 4.20 & 1.14 & 0.43 & 0.81 \\
\hline 12 & 5.29 & 3.56 & 4.59 & 6.31 & 12 & 4.80 & 2.43 & 0.70 & 1.05 \\
\hline Gdp shock (\%) & $\mathrm{hb}$ & spread & debt & vix & & & & & \\
\hline 1 & 4.84 & 1.04 & 4.01 & 0.00 & & & & & \\
\hline 2 & 4.63 & 2.44 & 4.51 & 1.39 & & & & & \\
\hline 3 & 4.74 & 3.22 & 4.68 & 1.57 & & & & & \\
\hline 4 & 4.95 & 3.72 & 4.81 & 1.63 & & & & & \\
\hline 8 & 5.76 & 4.54 & 5.10 & 2.06 & & & & & \\
\hline 12 & 6.42 & 4.72 & 5.09 & 2.45 & & & & & \\
\hline
\end{tabular}

Table 3: Variance decomposition - Whole sample 2008-2014

\begin{tabular}{|c|c|c|c|c|c|c|c|c|c|}
\hline Vix shock (\%) & $\mathrm{hb}$ & spread & debt & gdp & Spread shock (\%) & $\mathrm{hb}$ & debt & gdp & vix \\
\hline 1 & 0.72 & 0.25 & 0.00 & 0.00 & 1 & 3.59 & 0.00 & 0.00 & 0.00 \\
\hline 2 & 2.96 & 0.57 & 0.62 & 7.06 & 2 & 3.54 & 0.02 & 0.21 & 0.02 \\
\hline 3 & 5.00 & 1.09 & 1.65 & 8.74 & 3 & 3.47 & 0.06 & 0.37 & 0.05 \\
\hline 4 & 6.73 & 1.60 & 2.60 & 9.37 & 4 & 3.51 & 0.12 & 0.54 & 0.10 \\
\hline 8 & 10.20 & 2.63 & 4.60 & 9.51 & 8 & 3.97 & 0.54 & 1.20 & 0.30 \\
\hline 12 & 11.09 & 2.66 & 4.91 & 9.37 & 12 & 4.62 & 1.22 & 1.79 & 0.45 \\
\hline Debt shock (\%) & $\mathrm{hb}$ & spread & gdp & vix & $\mathrm{Hb}$ shock $(\%)$ & spread & debt & gdp & vix \\
\hline 1 & 12.46 & 10.39 & 4.88 & 0.00 & 1 & 3.69 & 0.00 & 0.00 & 0.00 \\
\hline 2 & 14.46 & 9.90 & 4.52 & 0.03 & 2 & 3.60 & 0.09 & 0.30 & 0.01 \\
\hline 3 & 16.42 & 9.77 & 4.43 & 0.10 & 3 & 3.62 & 0.32 & 0.57 & 0.05 \\
\hline 4 & 18.42 & 9.78 & 4.44 & 0.19 & 4 & 3.70 & 0.67 & 0.85 & 0.09 \\
\hline 8 & 26.27 & 10.47 & 4.72 & 0.74 & 8 & 4.44 & 3.15 & 1.89 & 0.27 \\
\hline 12 & 33.53 & 11.86 & 5.30 & 1.43 & 12 & 5.49 & 6.86 & 2.64 & 0.37 \\
\hline Gdp shock (\%) & $\mathrm{hb}$ & spread & debt & vix & & & & & \\
\hline 1 & 2.59 & 2.17 & 4.62 & 0.00 & & & & & \\
\hline 2 & 2.46 & 5.09 & 5.23 & 0.31 & & & & & \\
\hline 3 & 2.43 & 5.74 & 5.31 & 0.36 & & & & & \\
\hline 4 & 2.44 & 6.06 & 5.33 & 0.39 & & & & & \\
\hline 8 & 2.59 & 6.08 & 5.41 & 0.54 & & & & & \\
\hline 12 & 2.79 & 5.66 & 5.31 & 0.67 & & & & & \\
\hline
\end{tabular}

Table 4: Variance decomposition - Panel of 4 countries (Greece, Ireland, Italy, Spain) 


\begin{tabular}{|c|c|c|c|c|c|c|c|c|c|}
\hline Vix shock (\%) & $\mathrm{hb}$ & spread & debt & gdp & Spread shock (\%) & $\mathrm{hb}$ & debt & gdp & vix \\
\hline 1 & 0.49 & 0.61 & 0.00 & 0.00 & 1 & 2.82 & 0.00 & 0.00 & 0.00 \\
\hline 2 & 1.15 & 0.63 & 0.33 & 0.07 & 2 & 2.78 & 0.07 & 0.03 & 0.02 \\
\hline 3 & 2.06 & 0.73 & 0.96 & 0.07 & 3 & 2.77 & 0.20 & 0.03 & 0.07 \\
\hline 4 & 3.06 & 0.86 & 1.74 & 0.09 & 4 & 2.76 & 0.40 & 0.05 & 0.15 \\
\hline 8 & 7.09 & 1.38 & 5.13 & 0.11 & 8 & 2.93 & 1.52 & 0.08 & 0.69 \\
\hline 12 & 10.46 & 1.87 & 7.68 & 0.13 & 12 & 3.34 & 2.94 & 0.11 & 1.47 \\
\hline Debt shock (\%) & $\mathrm{hb}$ & spread & gdp & vix & Hb shock (\%) & spread & debt & gdp & vix \\
\hline 1 & 29.26 & 0.40 & 4.03 & 0.00 & 1 & 4.11 & 0.00 & 0.00 & 0.00 \\
\hline 2 & 30.02 & 0.43 & 4.03 & 0.01 & 2 & 4.17 & 0.01 & 0.01 & 0.01 \\
\hline 3 & 30.73 & 0.44 & 4.03 & 0.03 & 3 & 4.29 & 0.03 & 0.01 & 0.03 \\
\hline 4 & 31.33 & 0.46 & 4.03 & 0.05 & 4 & 4.44 & 0.07 & 0.01 & 0.05 \\
\hline 8 & 33.27 & 0.66 & 4.04 & 0.22 & 8 & 5.17 & 0.28 & 0.02 & 0.27 \\
\hline 12 & 34.93 & 1.04 & 4.05 & 0.53 & 12 & 6.26 & 0.58 & 0.03 & 0.58 \\
\hline Gdp shock (\%) & $\mathrm{hb}$ & spread & debt & vix & & & & & \\
\hline 1 & 1.61 & 0.38 & 4.29 & 0.00 & & & & & \\
\hline 2 & 2.35 & 0.84 & 4.83 & 0.13 & & & & & \\
\hline 3 & 2.26 & 0.74 & 4.66 & 0.12 & & & & & \\
\hline 4 & 2.31 & 0.74 & 4.59 & 0.13 & & & & & \\
\hline 8 & 2.32 & 0.68 & 4.17 & 0.16 & & & & & \\
\hline 12 & 2.33 & 0.67 & 3.88 & 0.22 & & & & & \\
\hline
\end{tabular}

Table 5: Variance decomposition - Ireland

\begin{tabular}{|c|c|c|c|c|c|c|c|c|c|}
\hline Vix shock (\%) & hb & spread & debt & gdp & Spread shock (\%) & $\mathrm{hb}$ & debt & gdp & vix \\
\hline 1 & 0.48 & 0.76 & 0.00 & 0.00 & 1 & 4.07 & 0.00 & 0.00 & 0.00 \\
\hline 2 & 0.68 & 0.87 & 0.10 & 2.18 & 2 & 4.32 & 0.03 & 0.09 & 0.03 \\
\hline 3 & 0.85 & 0.98 & 0.39 & 3.13 & 3 & 5.06 & 0.10 & 0.16 & 0.12 \\
\hline 4 & 1.00 & 1.09 & 0.80 & 3.90 & 4 & 6.09 & 0.22 & 0.25 & 0.26 \\
\hline 8 & 1.51 & 1.59 & 2.84 & 5.36 & 8 & 14.40 & 1.15 & 0.68 & 1.18 \\
\hline 12 & 1.91 & 2.05 & 4.73 & 5.80 & 12 & 27.30 & 2.67 & 1.13 & 2.33 \\
\hline Debt shock (\%) & $\mathrm{hb}$ & spread & gdp & vix & Hb shock $(\%)$ & spread & debt & gdp & vix \\
\hline 1 & 0.40 & 0.41 & 4.12 & 0.00 & 1 & 4.09 & 0.00 & 0.00 & 0.00 \\
\hline 2 & 0.52 & 0.47 & 4.02 & 0.05 & 2 & 4.06 & 0.00 & 0.01 & 0.01 \\
\hline 3 & 0.57 & 0.48 & 3.98 & 0.06 & 3 & 4.09 & 0.02 & 0.02 & 0.03 \\
\hline 4 & 0.64 & 0.50 & 3.96 & 0.07 & 4 & 4.16 & 0.03 & 0.03 & 0.06 \\
\hline 8 & 1.15 & 0.60 & 3.88 & 0.16 & 8 & 4.60 & 0.16 & 0.08 & 0.32 \\
\hline 12 & 1.79 & 0.80 & 3.85 & 0.29 & 12 & 5.27 & 0.37 & 0.16 & 0.71 \\
\hline Gdp shock (\%) & $\mathrm{hb}$ & spread & debt & vix & & & & & \\
\hline 1 & 0.71 & 0.63 & 4.14 & 0.00 & & & & & \\
\hline 2 & 2.34 & 1.84 & 5.07 & 1.38 & & & & & \\
\hline 3 & 2.37 & 2.04 & 5.10 & 1.47 & & & & & \\
\hline 4 & 2.31 & 2.22 & 5.08 & 1.51 & & & & & \\
\hline 8 & 1.80 & 2.64 & 4.90 & 1.43 & & & & & \\
\hline 12 & 1.60 & 2.94 & 4.63 & 1.45 & & & & & \\
\hline
\end{tabular}

Table 6: Variance decomposition - Italy 


\begin{tabular}{|c|c|c|c|c|c|c|c|c|c|}
\hline Vix shock $(\%)$ & $\mathrm{hb}$ & spread & debt & gdp & Spread shock (\%) & $\mathrm{hb}$ & debt & gdp & vix \\
\hline 1 & 3.04 & 0.40 & 0.00 & 0.00 & 1 & 3.77 & 0.00 & 0.00 & 0.00 \\
\hline 2 & 3.01 & 0.55 & 1.17 & 2.94 & 2 & 3.85 & 0.01 & 0.05 & 0.04 \\
\hline 3 & 2.87 & 0.81 & 3.36 & 3.84 & 3 & 4.06 & 0.04 & 0.10 & 0.14 \\
\hline 4 & 2.80 & 1.11 & 6.06 & 4.66 & 4 & 4.38 & 0.09 & 0.16 & 0.28 \\
\hline 8 & 2.97 & 2.52 & 16.74 & 5.83 & 8 & 6.85 & 0.45 & 0.43 & 1.18 \\
\hline 12 & 3.44 & 3.88 & 23.72 & 6.03 & 12 & 11.27 & 1.02 & 0.70 & 2.19 \\
\hline Debt shock (\%) & $\mathrm{hb}$ & spread & gdp & vix & Hb shock (\%) & spread & debt & gdp & vix \\
\hline 1 & 2.12 & 0.38 & 4.13 & 0.00 & 1 & 3.96 & 0.00 & 0.00 & 0.00 \\
\hline 2 & 2.09 & 0.42 & 4.00 & 0.03 & 2 & 4.07 & 0.03 & 0.03 & 0.08 \\
\hline 3 & 2.03 & 0.45 & 3.96 & 0.06 & 3 & 4.28 & 0.12 & 0.06 & 0.27 \\
\hline 4 & 1.96 & 0.50 & 3.92 & 0.09 & 4 & 4.58 & 0.28 & 0.10 & 0.56 \\
\hline 8 & 1.67 & 0.75 & 3.87 & 0.30 & 8 & 6.23 & 1.57 & 0.38 & 2.57 \\
\hline 12 & 1.45 & 1.10 & 3.87 & 0.58 & 12 & 8.30 & 3.77 & 0.77 & 5.12 \\
\hline Gdp shock (\%) & $\mathrm{hb}$ & spread & debt & vix & & & & & \\
\hline 1 & 0.44 & 0.40 & 4.16 & 0.00 & & & & & \\
\hline 2 & 0.96 & 0.68 & 4.29 & 0.78 & & & & & \\
\hline 3 & 0.91 & 0.65 & 4.19 & 0.78 & & & & & \\
\hline 4 & 0.90 & 0.67 & 4.06 & 0.80 & & & & & \\
\hline 8 & 0.87 & 0.74 & 3.53 & 0.79 & & & & & \\
\hline 12 & 0.86 & 0.82 & 3.06 & 0.86 & & & & & \\
\hline
\end{tabular}

Table 7: Variance decomposition - Spain

\begin{tabular}{|c|c|c|c|c|c|c|c|c|c|}
\hline Vix shock (\%) & hb & spread & debt & gdp & Spread shock (\%) & hb & debt & gdp & vix \\
1 & 0.75 & 0.67 & 0.00 & 0.00 & 1 & 4.47 & 0.00 & 0.00 & 0.00 \\
2 & 2.50 & 1.21 & 0.13 & 0.58 & 2 & 5.82 & 0.05 & 0.04 & 0.02 \\
3 & 4.69 & 1.75 & 0.34 & 0.66 & 3 & 8.23 & 0.18 & 0.05 & 0.07 \\
4 & 6.69 & 2.26 & 0.58 & 0.76 & 4 & 11.61 & 0.39 & 0.07 & 0.13 \\
8 & 10.16 & 3.57 & 1.53 & 0.87 & 8 & 26.08 & 2.38 & 0.15 & 0.51 \\
12 & 9.71 & 4.19 & 2.42 & 0.93 & 12 & 34.99 & 6.32 & 0.23 & 1.01 \\
\hline Debt shock (\%) & hb & spread & gdp & vix & Hb shock (\%) & spread & debt & gdp & vix \\
1 & 0.72 & 2.80 & 4.32 & 0.00 & 1 & 4.18 & 0.00 & 0.00 & 0.00 \\
2 & 1.66 & 3.13 & 4.41 & 0.10 & 2 & 4.02 & 0.11 & 0.06 & 0.05 \\
3 & 3.30 & 3.37 & 4.44 & 0.25 & 3 & 3.98 & 0.33 & 0.08 & 0.14 \\
4 & 5.55 & 3.59 & 4.48 & 0.42 & 4 & 4.03 & 0.61 & 0.10 & 0.25 \\
8 & 14.52 & 4.10 & 4.59 & 1.15 & 8 & 4.38 & 1.86 & 0.15 & 0.68 \\
12 & 19.40 & 4.33 & 4.65 & 1.80 & 12 & 4.87 & 2.79 & 0.18 & 0.96 \\
\hline Gdp shock (\%) & hb & spread & debt & vix & & & & & \\
2 & 0.88 & 1.05 & 4.53 & 0.00 & & & & & \\
3 & 1.49 & 1.90 & 5.26 & 0.78 & & & & & \\
4 & 1.45 & 1.83 & 5.13 & 0.79 & & & & &
\end{tabular}

Table 8: Variance decomposition - Portugal 


\begin{tabular}{|c|c|c|c|c|c|c|c|c|c|}
\hline Vix shock (\%) & hb & spread & debt & gdp & Spread shock (\%) & $\mathrm{hb}$ & debt & gdp & vix \\
\hline 1 & 0.33 & 0.28 & 0.00 & 0.00 & 1 & 0.25 & 0.00 & 0.00 & 0.00 \\
\hline 2 & 1.67 & 0.35 & 0.61 & 6.87 & 2 & 0.23 & 0.02 & 0.31 & 0.02 \\
\hline 3 & 3.05 & 0.51 & 1.72 & 8.87 & 3 & 0.25 & 0.07 & 0.62 & 0.06 \\
\hline 4 & 4.30 & 0.64 & 2.81 & 9.60 & 4 & 0.28 & 0.17 & 0.94 & 0.11 \\
\hline 8 & 7.59 & 0.94 & 5.57 & 9.78 & 8 & 0.45 & 0.98 & 2.12 & 0.38 \\
\hline 12 & 9.22 & 1.00 & 6.51 & 9.60 & 12 & 0.66 & 2.42 & 3.02 & 0.55 \\
\hline Debt shock (\%) & $\mathrm{hb}$ & spread & gdp & vix & Hb shock $(\%)$ & spread & debt & gdp & vix \\
\hline 1 & 13.50 & 7.84 & 5.64 & 0.54 & 1 & 0.00 & 0.00 & 0.00 & 0.00 \\
\hline 2 & 15.18 & 6.97 & 5.25 & 0.52 & 2 & 0.01 & 0.04 & 0.13 & 0.01 \\
\hline 3 & 16.87 & 6.77 & 5.11 & 0.54 & 3 & 0.03 & 0.14 & 0.26 & 0.02 \\
\hline 4 & 18.53 & 6.72 & 5.06 & 0.66 & 4 & 0.07 & 0.31 & 0.40 & 0.04 \\
\hline 8 & 24.87 & 7.43 & 5.25 & 1.56 & 8 & 0.35 & 1.55 & 0.95 & 0.12 \\
\hline 12 & 30.71 & 8.71 & 5.75 & 2.51 & 12 & 0.75 & 3.59 & 1.42 & 0.18 \\
\hline Gdp shock (\%) & $\mathrm{hb}$ & spread & debt & vix & & & & & \\
\hline 1 & 1.16 & 2.30 & 0.00 & 2.88 & & & & & \\
\hline 2 & 1.21 & 5.38 & 0.78 & 4.37 & & & & & \\
\hline 3 & 1.31 & 6.47 & 1.28 & 4.71 & & & & & \\
\hline 4 & 1.42 & 7.07 & 1.68 & 4.83 & & & & & \\
\hline 8 & 1.76 & 7.85 & 2.78 & 4.90 & & & & & \\
\hline 12 & 2.00 & 7.76 & 3.49 & 4.84 & & & & & \\
\hline
\end{tabular}

Table 9: Variance decomposition - Whole sample, first Cholesky decomposition

\begin{tabular}{|c|c|c|c|c|c|c|c|c|c|}
\hline Vix shock (\%) & $\mathrm{hb}$ & spread & debt & gdp & Spread shock (\%) & $\mathrm{hb}$ & debt & gdp & vix \\
\hline 1 & 0.34 & 0.29 & 0.00 & 0.00 & 1 & 0.24 & 0.00 & 0.00 & 0.00 \\
\hline 2 & 1.71 & 0.36 & 0.60 & 6.97 & 2 & 0.22 & 0.02 & 0.32 & 0.02 \\
\hline 3 & 3.11 & 0.50 & 1.69 & 9.00 & 3 & 0.24 & 0.07 & 0.62 & 0.06 \\
\hline 4 & 4.36 & 0.63 & 2.79 & 9.72 & 4 & 0.27 & 0.17 & 0.94 & 0.12 \\
\hline 8 & 7.66 & 0.91 & 5.53 & 9.93 & 8 & 0.46 & 0.98 & 2.14 & 0.38 \\
\hline 12 & 9.34 & 0.97 & 6.41 & 9.74 & 12 & 0.67 & 2.45 & 3.03 & 0.55 \\
\hline Debt shock (\%) & $\mathrm{hb}$ & spread & gdp & vix & Hb shock (\%) & spread & debt & gdp & vix \\
\hline 1 & 11.09 & 9.53 & 0.00 & 0.24 & 1 & 0.00 & 0.00 & 0.00 & 0.00 \\
\hline 2 & 12.60 & 9.53 & 0.02 & 0.26 & 2 & 0.01 & 0.04 & 0.13 & 0.01 \\
\hline 3 & 14.02 & 9.67 & 0.05 & 0.38 & 3 & 0.03 & 0.14 & 0.26 & 0.02 \\
\hline 4 & 15.40 & 9.85 & 0.11 & 0.54 & 4 & 0.07 & 0.31 & 0.40 & 0.04 \\
\hline 8 & 20.60 & 10.94 & 0.47 & 1.42 & 8 & 0.35 & 1.54 & 0.96 & 0.12 \\
\hline 12 & 25.51 & 12.47 & 1.00 & 2.31 & 12 & 0.76 & 3.59 & 1.43 & 0.17 \\
\hline Gdp shock (\%) & $\mathrm{hb}$ & spread & debt & vix & & & & & \\
\hline 1 & 3.78 & 0.67 & 5.75 & 3.19 & & & & & \\
\hline 2 & 3.97 & 2.82 & 9.36 & 4.65 & & & & & \\
\hline 3 & 4.39 & 3.56 & 10.9 & 74.91 & & & & & \\
\hline 4 & 4.77 & 3.96 & 12.0 & 44.95 & & & & & \\
\hline 8 & 6.18 & 4.32 & 14.3 & 34.91 & & & & & \\
\hline 12 & 7.32 & 4.11 & 15.2 & 14.92 & & & & & \\
\hline
\end{tabular}

Table 10: Variance decomposition - Whole sample, second Cholesky decomposition 


\begin{tabular}{|c|c|c|c|c|c|c|c|c|c|}
\hline Vix shock (\%) & $\mathrm{hb}$ & spread & debt & gdp & Spread shock (\%) & $\mathrm{hb}$ & debt & gdp & vix \\
\hline 1 & 0.33 & 0.29 & 0.00 & 96.20 & 1 & 0.00 & 0.00 & 0.00 & 0.00 \\
\hline 2 & 1.72 & 0.36 & 6.90 & 94.67 & 2 & 0.02 & 0.02 & 0.33 & 0.02 \\
\hline 3 & 3.12 & 0.50 & 8.93 & 94.26 & 3 & 0.05 & 0.08 & 0.65 & 0.06 \\
\hline 4 & 4.38 & 0.64 & 9.65 & 93.88 & 4 & 0.09 & 0.18 & 0.99 & 0.12 \\
\hline 8 & 7.67 & 0.90 & 9.84 & 92.35 & 8 & 0.28 & 1.08 & 2.24 & 0.39 \\
\hline 12 & 9.31 & 0.96 & 9.67 & 90.95 & 12 & 0.50 & 2.69 & 3.20 & 0.58 \\
\hline Debt shock (\%) & $\mathrm{hb}$ & spread & gdp & vix & Hb shock (\%) & spread & debt & gdp & vix \\
\hline 1 & 13.85 & 7.63 & 5.72 & 0.52 & 1 & 0.28 & 0.00 & 0.00 & 0.00 \\
\hline 2 & 15.56 & 6.82 & 5.31 & 0.51 & 2 & 0.25 & 0.04 & 0.11 & 0.01 \\
\hline 3 & 17.25 & 6.62 & 5.16 & 0.54 & 3 & 0.25 & 0.13 & 0.23 & 0.02 \\
\hline 4 & 18.93 & 6.58 & 5.12 & 0.66 & 4 & 0.27 & 0.29 & 0.35 & 0.03 \\
\hline 8 & 25.20 & 7.34 & 5.32 & 1.55 & 8 & 0.49 & 1.45 & 0.84 & 0.11 \\
\hline 12 & 31.05 & 8.70 & 5.80 & 2.50 & 12 & 0.76 & 3.37 & 1.25 & 0.16 \\
\hline Gdp shock (\%) & $\mathrm{hb}$ & spread & debt & vix & & & & & \\
\hline 1 & 1.21 & 2.31 & 0.00 & 2.79 & & & & & \\
\hline 2 & 1.24 & 5.31 & 0.77 & 4.30 & & & & & \\
\hline 3 & 1.34 & 6.37 & 1.26 & 4.65 & & & & & \\
\hline 4 & 1.46 & 6.95 & 1.66 & 4.79 & & & & & \\
\hline 8 & 1.82 & 7.74 & 2.74 & 4.84 & & & & & \\
\hline 12 & 2.04 & 7.65 & 3.45 & 4.80 & & & & & \\
\hline
\end{tabular}

Table 11: Variance decomposition - Whole sample, third Cholesky decomposition 